\title{
First Assessment of SMOS Data Over Open Ocean: Part II-Sea Surface Salinity
}

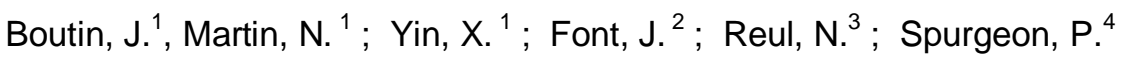 \\ ${ }^{1}$ Institut Pierre-Simon Laplace, Laboratoire d'Océanographie et du Climat-Expérimentation et Approches \\ Numériques (LOCEAN), Unité Mixte de Recherche Université Pierre et Marie Curie-Centre National de la \\ Recherche Scientifique-Institut de Recherche pour le Développement-Muséum National d'Histoire Naturelle, \\ Paris, 75252 France \\ ${ }^{2}$ Ciències del Mar, Centre Mediterrani d'Investigacions Marines i Ambientals (CMIMA)-Consejo Superior de \\ Investigaciones Cientificas (CSIC), 08003 Barcelona, Spain \\ ${ }^{3}$ Institut Français de Recherche pour l'Exploitation de la Mer (IFREMER), 29280 Plouzané, France \\ ${ }^{4}$ Spurgeon is with ARGANS, Plymouth, PL6 8BT United Kingdom \\ *: Corresponding author : email address : $\underline{\mathrm{b} @ @ l o c e a n-i p s l . u p m c . f r}$, nicolas.martin@locean-ipsl.upmc.fr , \\ xiaobin.yin@locean-ipsl.upmc.fr, jfont@icm.csic.es, Nicolas.Reul@ifremer.fr, PSpurgeon@argans.co.uk
}

\begin{abstract}
:
We validate Soil Moisture and Ocean Salinity (SMOS) sea surface salinity (SSS) retrieved during August 2010 from the European Space Agency SMOS processing. Biases appear close to land and ice and between ascending and descending orbits; they are linked to image reconstruction issues and instrument calibration and remain under study. We validate the SMOS SSS in conditions where these biases appear to be small. We compare SMOS and ARGO SSS over four regions far from land and ice using only ascending orbits. Four modelings of the impact of the wind on the sea surface emissivity have been tested. Results suggest that the L-band brightness temperature is not linearly related to the wind speed at high winds as expected in the presence of emissive foam, but that the foam effect is less than previously modeled. Given the large noise on individual SMOS measurements, a precision suitable for oceanographic studies can only be achieved after averaging SMOS SSS. Over selected regions and after mean bias removal, the precision on SSS retrieved from ascending orbits and averaged over $100 \mathrm{~km}$ \$times $\$ 100 \mathrm{~km}$ and 10 days is between 0.3 and $0.5 \mathrm{pss}$ far from land and sea ice borders. These results have been obtained with forward models not fitted to satellite L-band measurements, and image reconstruction and instrument calibration are expected to improve. Hence, we anticipate that deducing, from SMOS measurements, SSS maps at $200 \mathrm{~km} \$$ times $\$ 200 \mathrm{~km}, 10$ days resolution with an accuracy of 0.2 pss at a global scale is not out of reach.
\end{abstract}

Keywords: L-Band, Microwave Radiometry, Ocean Salinity, Sea Surface 


\section{Introduction}

SINCE the seventies, satellite oceanography has made huge progresses and today satellite observations over the ocean are key components of the global climate observing systems (GCOS). While sea surface temperature, sea level, sea ice and sea state are relatively well monitored [1], until 2009, sea surface salinity (SSS) was not measured from space although salinity is recognized as an essential climate variable [2] and satellite SSS is expected to be very complementary to existing in situ salinity measurements [3].

The feasibility of measuring SSS from space was first demonstrated in the frame of the Skylab mission launched in 1973 [4]. However, at L-band, the sensitivity of radiometric measurements to the salinity is low and the radiometric resolution of the instruments remained an obstacle to the development of new satellite missions until the nineties. Then, the development of new technologies [5] has contributed to a renewed interest in L-band radiometry. This led to two satellite missions accepted by space agencies: the Soil Moisture and Ocean Salinity (SMOS) mission of the European Space Agency and the Aquarius/SACD mission of the NASA/CONAE agencies. SMOS uses a new antenna concept (synthetic aperture) for spaceborne radiometry applications and was successfully launched in November 2009; Aquarius uses a large size real aperture antenna and has been launched in June 2011. The goal of these two missions is to achieve accuracy on the SSS averaged over $150-200 \mathrm{~km}$ and one month of $\sim 0.2$ pss (pss is for practical salinity scale as recommended by [6]) or better.

An overview of the retrieval of SSS from SMOS measurements since SMOS launch is given in [7].

In this paper, we concentrate on the assessment of the quality of the SSS retrieved from one month of SMOS measurements using radiative transfer models defined before SMOS launch and implemented in the ESA level 2 processor. We describe data and methods in section II, results are 
presented in section III and discussed in section IV.

\section{DATA AND METHODS}

\section{A. SMOS processing}

The SMOS 2-D interferometric concept [8][9] allows the instrument to perform measurements over two-dimensional snapshots so that a grid point over the ocean is seen by numerous independent snapshots under various incidence and azimuth angles. The retrieval of SSS is based on a maximum likelihood Bayesian approach [10][11]. The SMOS brightness temperatures $\mathrm{TB}^{\text {meas }}$ reconstructed at different incidence angles are fitted to TB modeled in the antenna reference frame, using forward models described below, $\mathrm{TB}^{\text {mod, }}$ by minimizing the cost function:

$\chi^{2}=\sum_{n=1}^{N} \frac{\left[T B_{n}^{\text {meas }}-T B_{n}^{\bmod }\left(\theta_{n}, P_{i} \ldots\right)\right]^{2}}{\sigma_{T B n}^{2}}+\sum_{i=1}^{M} \frac{\left[P_{i}-P_{i 0}\right]^{2}}{\sigma_{P i 0}^{2}}$

$\mathrm{N}$ is the number of SMOS measurements available for SSS retrieval at different incidence angles $\theta_{\mathrm{n}}$ in the four polarizations. $\mathrm{TB}_{\mathrm{n}}{ }^{\mathrm{mod}}$ are simulated at incidence angles $\theta_{\mathrm{n}}$ using forward model, with $\sigma_{\mathrm{TBn}}{ }^{2}=\sigma_{\mathrm{TB} \_ \text {meas_n }}{ }^{2}+\sigma_{\mathrm{TB} \_ \text {model_n }}{ }^{2}$. $\sigma_{\mathrm{TB} \_ \text {meas_n }}$ is the instrumental expected rms error on $\mathrm{TB}^{\text {meas }}$ simulated by the $\mathrm{L} 1 \mathrm{C}$ processor and $\sigma_{\mathrm{TB} \_ \text {model_n }}$ is an estimate of the model error. Both are given in the antenna reference frame. The geophysical parameters of the forward model, $\mathrm{P}_{\mathrm{i}}$, include SSS, SST and sea surface roughness descriptors. M is the number of retrieved geophysical parameters; $\mathrm{P}_{\mathrm{i} 0}$ are a priori estimates of the $\mathrm{P}_{\mathrm{i}}$ with a priori variances $\sigma_{\mathrm{Pi} 0}{ }^{2} . \mathrm{P}_{\mathrm{i} 0}$ values are specified a priori. A general least square iterative algorithm [12] is used to retrieve the $P_{i}$ values that minimize the cost function (Eq. 1), and this algorithm provides estimates of the theoretical variances $\sigma_{\mathrm{Pi}}{ }^{2}$ of the retrieved parameters.

The forward models that simulate SMOS measurements use the physical modelling of atmospheric radiative transfer [13], and take into account the occurrence of the galactic glints [14][15]; the sea surface emissivity modelling is separated in several components: the perfectly flat sea component estimated with the model of [16] plus a rough sea and foaminduced components. Four parameterizations for describing these rough/foam effects based on electromagnetic modelling of sea surface scattering or empirically derived from radiometric measurements performed from an oil rig and from an aircraft have been tested:

-1- the model 1 implemented in SMOS level 2 processor neglects the foam influence and simulates the rough sea using a two scale model that uses the [17] wave spectrum multiplied by a factor two [18][19].

- 2- the model 2 implemented in SMOS level 2 processor models the emissivity of a rough sea from the small-slope approximation model [20][21] and uses the Kudryavtsev wave spectrum [22]. In addition to the rough sea emissivity, model 2 considers the foam emissivity. It partitions the ocean surface into foam-free and foam-covered areas [23], and it includes a specific foam emissivity model to account for the effect of the presence of foam on the sea surface emission. Foam contribution can have a significant impact for wind speed in excess of $10-12 \mathrm{~m} \cdot \mathrm{s}^{-1}$ at L-band [24].

Theoretical models 1 and 2 have been compared with experimental data previous to SMOS launch with reasonable agreement [25][26].

- 3- the model 3 (WISE model) implemented in SMOS level 2 processor is a semiempirical model derived from the Wind and Salinity Experiment (WISE) in 2000-2001 during which a polarimetric L-band radiometer was mounted on an oil rig in the Mediterranean Sea while extensive oceanic and meteorological measurements were performed[27][28]. It describes the increment of TB due to the roughness of the sea as function of wind speed and significant wave height. Model 3 has been found to perform fairly well to retrieve sea surface salinity from airborne radiometric measurements acquired in a region characterized by a large range of oceanographic conditions [29].

-4- the PALS (Passive/Active L-band Sensor) model [30] has been derived recently from PALS airborne data obtained over a large wind speed range (between 4 and $28 \mathrm{~m} \cdot \mathrm{s}^{-1}$ ). At a given incidence angle, it relates linearly the L-band brightness temperatures to wind speed. The measurements during circles indicate an influence of the azimuth direction (up to $1.5 \mathrm{~K}$ at $30^{\circ}$ and $24 \mathrm{~m} . \mathrm{s}^{-1}$ ) but this was obtained only for a limited number of wind speeds and incidence angles. We tested two azimuth dependencies: one extrapolated from PALS measurements over SMOS incidence angles and the whole range of wind speeds (Yueh, pers. comm.), and one derived from model 1. The SSS retrieved with these two azimuth dependencies were not significantly different so that we decided in the following to use the azimuthal dependency simulated by model 1 .

The dependency of the four models with respect to wind speed is summarized on Fig. 1. Above $7 \mathrm{~m} . \mathrm{s}^{-1}$, model 2 is highly non linearly evolving with wind speed due to the inclusion of foam effects. At moderate incidence angle, the sensitivity of the PALS and WISE models to wind speed is smaller than model 1 and 2 at low wind speed (less than $4 \mathrm{~m} / \mathrm{s}$ ) whereas at larger wind speed, up to $15 \mathrm{~m} \cdot \mathrm{s}^{-1}$, and in vertical polarization, they predict a stronger impact with wind speed . The sensitivity of the PALS model to incidence angle is much smaller than the one of the three other models; variations with incidence angle of models 1 and 2 are quite close whereas the dependence of model 3 with incidence angle is linear (see Fig. 1 in [11]).

By default in the ESA processor, SSS is retrieved with model 1 with two additional SSS products generated using model 2 and 3.

In this paper, SSS is retrieved from SMOS brightness temperatures produced in real time by the SMOS operational chain that uses the ESA SMOS level 1c processor v344. We choose to use the SMOS data produced from $3^{\text {rd }}$ to $31^{\text {st }}$ of August 2010, a period during which the calibration parameters 
and the algorithms used in the L1c processor were stable, contrary to previous periods.

SSS is retrieved using the ESA level 2 processor version 316 that uses the forward models and the retrieval algorithms described in [11]. After this version has been implemented in the operational chain, we found inconsistencies in the wind direction convention used for model 1 ; we corrected for the bug and a corrected version of the processor has been rerun on LOCEAN machines for the whole month of August. This bug had a small influence on the retrieved SSS itself except at low wind speed (below $3 \mathrm{~m} \cdot \mathrm{s}^{-1}$ ) and it hampered a rapid convergence of the retrieval. It has been corrected in version v317 of the level 2 processor.

When comparing SMOS TBs and modelled TBs, systematic image reconstruction biases have been evidenced as depending on the location in the field of view (see [7] and companion paper [31]). These systematic biases were estimated over an ascending orbit in the south east Pacific between $50^{\circ} \mathrm{S}$ and $10^{\circ} \mathrm{N}$ on 5th August by averaging the difference at antenna level between SMOS measurements and the forward model predictions evaluated using the WOA2005 climatology. The resulting two-dimensional bias estimated from the $5^{\text {th }}$ August orbit has been systematically removed from all August SMOS measurements. This bias removal (so called Ocean Target Transformation) has been computed separately for each tested forward model. It is assumed to remain constant over the August period. It is hoped that, in the future, improvements in image reconstruction and forward radiative transfer models will help to find the causes of this bias and reduce it.

$\mathrm{N}$ in (1) decreases from about 200 measurements at the center of the swath to a few measurements at the edge of the sub-satellite track. Typically, $\sigma_{\mathrm{TB} \_ \text {meas } \_n}$ ranges from 1.7 to 3.9 $\mathrm{K}$ for measurements integrated over $1.2 \mathrm{~s}$ (see companion paper [31]). In a first approach, we take the model error $\square_{\text {TB_model_n }}$ to be constant and equal to $0.5 \mathrm{~K}$ for the first and second Stokes parameters and $0.1 \mathrm{~K}$ for the third and fourth Stokes parameters. The auxiliary data required to specify prior parameters $\mathrm{P}_{\mathrm{i} 0}$ (SST, wind descriptors, atmospheric parameters) are obtained from the forecasts provided by the European Center for Medium-Range Weather Forecast (ECMWF). The level 1C product includes one Total Electron Content (TEC) value per snapshot, produced by the IGS (International Global Navigation Satellite System Service) (http://www.aiub.unibe.ch/content/research/gnss/code__resea rch/igs/global_ionosphere_maps_produced_by_code/index_en g.html). In case IGS data are not available, the level 1C processor uses TEC produced by the IRI2001 (International Reference Ionosphere) model instead (http://omniweb.gsfc.nasa.gov/vitmo/iri_vitmo.html). For each grid point, there are as many TEC values as TB values, so the median TEC is used as prior. The uncertainties $\square_{\mathrm{Pi} 0}$ associated with the geophysical parameters are set to $1^{\circ} \mathrm{C}$ on SST and 10TecU on TEC and, for model 1: $1.5 \mathrm{~m} \mathrm{~s}^{-1}$ on components of neutral wind speed, for model $2,0.05 \mathrm{~m} \mathrm{~s}^{-1}$ on friction velocity, $10 \%$ on inverse wave age and $5^{\circ}$ on wind direction; for PALS model, $2 \mathrm{~m} \cdot \mathrm{s}^{-1}$ on neutral wind speed; for model 3, 2 $\mathrm{m} . \mathrm{s}^{-1}$ on neutral wind speed and $10 \%$ on significant wave height. These values were chosen as rough estimates of the expected error of the ECMWF forecasts extrapolated at the time of SMOS measurement. The influence of these errors onto the SSS retrieval has been studied in [11]. The only exception is the sea surface salinity, which is left free during the retrieval procedure, by putting the SSS uncertainty equal to 100 pss. For technical reasons, the prior SSS is taken from the world ocean atlas (WOA 2005) [32] but we checked that the same SSS is retrieved if instead the prior SSS is set to 35 pss everywhere.

The equivalent footprint diameter assigned to each retrieved SSS is computed as the diameter of the equivalent circle which surface equals the mean surface of the SMOS measurements involved in the retrieval.

In this paper, we selected the SSS retrieved with a 'valid quality flag', with good fit indicators, sufficient number of TBs to be used in the retrieval $(>16)$, small number of measurements $(<10)$ possibly affected by sunglint, small number $(<50)$ of discarded outliers, number of iterations less than 20; details about the definition of these flags can be found in [25] and in [33] .

\section{B. Global maps of SSS}

10 days-100 km x $100 \mathrm{~km}$ resolution SSS maps are built by taking a weighted average of SMOS SSS. The weight is inversely proportional to the error variance of the retrieved SSS (that gives more weight to the best SSS retrievals) and to the mean equivalent surface of the pixel as follows:

$$
<S S S>=\left[\sum_{j=1}^{N} \frac{S S S_{j}}{R_{j}^{2} \sigma_{j}^{2}} / \sum_{j=1}^{N} \frac{1}{R_{j}^{2} \sigma_{j}^{2}}\right]
$$

Where, $\sigma_{j}$ is the error of retrieved SSS estimated during the retrieval process at a grid point $j$ and $R_{j}$ is the equivalent footprint diameter of the equivalent circle, centred on a grid point $j$, where SSS is retrieved. The area of the equivalent circle is equal to the mean surface of the footprint ellipses of the measurements entering in the SSS retrieval.

The weight by the surface of the pixel is because SMOS SSS are delivered over an oversampled grid (ISEA grid) at 15 $\mathrm{km}$ resolution whereas the actual resolution of independent SMOS measurements is variable (from about $30 \mathrm{~km}$ to 100 $\mathrm{km})$. A more complete justification of this formula is given in the appendix of our companion paper [31].

These maps are compared to the WOA05 SSS climatology built for the month of August. Although the WOA05 map does not reproduce interannual variability peculiar to the August 2010 month, it shows the main features of SSS spatial variability.

\section{ARGO data}

We use the ARGO SSS data between 29 July and 5 September 2010 distributed in near real time by the CORIOLIS data centre (http://www.coriolis.eu.org ). For most of the ARGO vertical profiles, we consider the measurement 
the closest to the sea surface between $0.5 \mathrm{~m}$ and $10 \mathrm{~m}$ depth. We do not take into account measurements which depth is between the surface and $0.5 \mathrm{~m}$ as we observed some spurious measurements close to the sea surface likely due to inaccuracies in the depth-pressure measurement. For SOLO and PROVOR profilers types, we only consider profiles between $5 \mathrm{~m}$ and $10 \mathrm{~m}$ because these profilers types do not pump water at a depth upper than $5 \mathrm{~m}$. We only consider measurements with flags of position, date, depth, temperature and salinity set to 1 (good) or 0 (not checked because of real time transmission).

Detailed comparisons have been performed in four regions of the global ocean (see color boxes on Fig. 2, bottom, left), two in the Southern Ocean characterized by very variable wind speed, and two in the Northern tropics and subtropics:

-in the Southern Pacific ocean $\left(50^{\circ} \mathrm{S} 45^{\circ} \mathrm{S}-180^{\circ} \mathrm{W} 100^{\circ} \mathrm{W}\right)$; mean (standard deviation) of SST and SSS are $9,8(1.8){ }^{\circ} \mathrm{C}$ and $34,4(0.2)$ pss respectively

-in the Southern Indian ocean $\left(40^{\circ} \mathrm{S}-30^{\circ} \mathrm{S}-70^{\circ} \mathrm{E}-90^{\circ} \mathrm{E}\right)$; mean (standard deviation) of SST and SSS are $14,8(2.0)^{\circ} \mathrm{C}$ and 35,4 (0.3) pss respectively

-in the Northern subtropical Atlantic ocean $\left(15^{\circ} \mathrm{N}-30^{\circ} \mathrm{N}-\right.$ $30^{\circ} \mathrm{W}-45^{\circ} \mathrm{W}$ ), characterized by very salty waters and relatively low SSS variability with respect to the tropical Pacific Ocean zone (see below); mean (standard deviation) of SST and SSS are $26,4(0.8)^{\circ} \mathrm{C}$ and $37.3(0.3)$ pss respectively

-in the Northern tropical Pacific ocean $\left(5^{\circ} \mathrm{N}-15^{\circ} \mathrm{N}-180^{\circ} \mathrm{W}\right.$ $110^{\circ} \mathrm{W}$ ): mean (standard deviation) of SST and SSS are 27,7 (0.6) ${ }^{\circ} \mathrm{C}$ and $34,1(0.6)$ pss respectively. This region is characterized by a low SSS anomaly with respect to the climatology (Fig. 2) and by a strong SSS variability, as seen on the standard deviation of ARGO SSS due to high precipitations in this area.

In the tropical Pacific Ocean, 225 ARGO profilers are of WEBB type and 33 are of SOLO type. In the Southern Ocean, half ARGO profilers are WEBB and half are SOLO. In the subtropical Atlantic Ocean, one third of ARGO profilers are WEBB type, two thirds SOLO. No influence of the type of float has been noticed in our comparisons.

SMOS SSS is colocated with ARGO SSS using colocation radii of $+/-5$ days and $+/-50 \mathrm{~km}$. Only SMOS SSS retrieved during ascending orbits is used in order to avoid imperfect estimate of galactic glint which is dominant in descending passes at this period of the year (Reul et al., 2008).

We will characterize the systematic difference between SMOS and ARGO colocated SSS by the median of the difference and by the standard deviation of the difference between both data sets.

Since SMOS SSS is very noisy at the edge of the swaths, in our analysis we will distinguish statistics performed using SSS over the whole swath and using SSS retrieved only at +/$300 \mathrm{~km}$ from the centre of the track where the number of TB measurements is much larger and the SSS error is much smaller [11].

Given the large errors of individual SMOS SSS, they will be averaged before being used for ocean process studies over typically $100 \mathrm{~km}$ and 10 days. In order to check that such an averaging process decreases the error of SMOS SSS, in addition to comparing each individual SMOS SSS with ARGO SSS, all SMOS SSS collocated with one ARGO measurement are averaged, each SMOS SSS being weighted by the mean surface of the pixel and by the error variance derived by the retrieval $\left(\sigma_{\mathrm{sss}}^{2}\right)$ (equation 2$)$.

Detailed analysis with models 1,2 and 3 have been performed in the 4 zones; SSS analysis retrieved with PALS model has been limited to Southern Pacific Ocean and Tropical Pacific Ocean in order to limit reprocessing at LOCEAN and because these two regions are representative of contrasted wind speed.

\section{RESULTS}

\section{A. Comparison to climatological SSS}

The spatial variability of SSS at a global scale is quite well reproduced on global maps of SMOS SSS (Fig. 3). In particular, salty waters in the tropical Atlantic Ocean, fresh waters in intertropical convergence zones, at high latitudes and in the Amazon plume are qualitatively consistent with the climatology. However, several flaws are evident on these maps and on the maps of the differences with respect to the climatology (Fig. 4):

-Large biases close to land and ice: biases as large as 2pss in absolute value are observed at several hundreds of $\mathrm{km}$ from large land masses and from ice edges. The sign, the magnitude and spatial extension of these biases are different for ascending and descending orbits.

- Far from land, in the Northern hemisphere, SSS on descending orbits are saltier than on ascending orbits whereas in the Southern hemisphere, SSS on descending orbits are fresher by a few tenths of pss (Fig. 3).

-Spots of anomalously low SSS are observed in the Southern Ocean; their location seems to occur in regions with spots of high wind speed (Fig. 4). This flaw will be studied in more details in our comparisons with ARGO SSS.

- Strips of low and high SSS values appear along tracks on maps of SSS retrieved during descending orbits (Fig. 3), possibly because of an imperfect galactic noise scattering correction as galactic signal is expected to be stronger during descending orbits in August [15] (Tenerelli, 2010, pers. comm.).

-Few SSS retrievals occur in the high Northern latitudes because of the presence of radio frequency interferences that raise the flag of anomalous measurements.

All these flaws are under study by the various teams working closely to SMOS instrument. In particular, the difference between ascending and descending orbit has been shown to be linked to the variation of the antennas losses with the physical temperature and to errors in the implementation of the sun correction in the image reconstruction procedure (Tenerelli and Martin Neira, pers. comm.) and this effect is going to be corrected in future data reprocessing. In the rest of 
this paper, we will concentrate on the precision of SMOS retrieved SSS in regions far from land and ice and during ascending orbits where these flaws are minima, with the hope that future studies will improve image reconstruction near land and ice and provide corrections for galactic noise.

\section{B. Comparison to ARGO SSS}

\section{SSS retrieved from model1}

The comparison of SMOS SSS to ARGO SSS (Fig. 2) evidences much more scatter than the comparison of ARGO SSS to the climatology, and again large biases in the vicinity of land and ice. ARGO SSS during August 2010 exhibits negative anomalies (<-0.5 pss) with respect to the climatology around $10^{\circ} \mathrm{N}$ in the Northern Pacific, around $15^{\circ} \mathrm{N}$ in the western Atlantic and positive anomalies $(>0.5 \mathrm{pss})$ in the western equatorial Pacific. All these anomalies are quite well captured by SMOS SSS (Fig. 2). Nevertheless, the anomaly in the tropical Pacific region is slightly fresher on SMOS SSS than on ARGO SSS (Fig. 2, bottom left) which motivate us to look in more detail to this area.

We closely analyse the comparisons in four regions far from land and ice, where no large biases are identified on the difference between ascending and descending SSS (Fig. 3). The statistics of the comparisons are given in Table 1. As expected from the decrease of $\partial \mathrm{TB} / \partial \mathrm{SSS}$ with the decrease in SST, the standard deviation of the SMOS SSS minus the ARGO SSS $(\sigma)$ is the largest in the coldest region: $\sigma$ is multiplied by a factor $\sim 1.5$ between the tropical Pacific and the Southern Pacific region; the error is reduced by a factor $\sim 1.5$ when only the centre of the swath is considered instead of the full swath. When the SSS differences are sorted in $1 \mathrm{~m} . \mathrm{s}^{-1}$ wind speed classes, it appears clearly that above $12 \mathrm{~m} \cdot \mathrm{s}^{-1}$ SMOS SSS are systematically underestimated (Fig. 5). The pattern is very similar for the various regions: biases averaged in classes of $1 \mathrm{~m} \cdot \mathrm{s}^{-1}$ wind speed are less than 0.3 pss between 3 and 12 $\mathrm{m} . \mathrm{s}^{-1}$ (11 m.s $\mathrm{s}^{-1}$ in the tropical Pacific Ocean); they are systematically negative above $12 \mathrm{~m} \cdot \mathrm{s}^{-1}$ and lower than -1 pss above $15 \mathrm{~m} . \mathrm{s}^{-1}$; they are larger in absolute value and different from one region to another below $3 \mathrm{~m} \cdot \mathrm{s}^{-1}$.

As expected, when the SMOS SSS are averaged over 100 $\mathrm{km}$ and 10 days around the ARGO measurement before comparison, $\sigma$ are reduced (Fig. 6, Table 2). The best improvement is observed when the whole $1200 \mathrm{~km}$ swath is considered. This confirms, over this particular month, results obtained during simulation studies performed previous to launch: although using the whole swath introduces data with larger noise in the average, it improves the average because of the increase of the number of data. With respect to results obtained on non averaged data, $\sigma$ is reduced by about a factor 3 in the Southern Pacific Ocean, in the Southern Indian Ocean, and in the subtropical Atlantic Ocean and by about a factor 2.5 in the tropical Pacific Ocean.

\section{SSS retrieved with model 2}

Between 2 and $15 \mathrm{~m} / \mathrm{s}$, biases averaged in classes of $1 \mathrm{~m} / \mathrm{s}$ wind speed are always less than 0.6 pss with a tendency of the bias to decrease as a function of wind speed between 7 an $12 \mathrm{~m} / \mathrm{s}$ in the Southern Pacific Ocean. Below $2 \mathrm{~m} . \mathrm{s}^{-1}$ biases are larger in absolute value and different from one region to another (Fig. 7). Above $15 \mathrm{~m} / \mathrm{s}$, SMOS SSS is overestimated, the overestimate being larger than 2 pss above $16 \mathrm{~m} / \mathrm{s}$. The statistics of these comparisons are reported in Table 3. Mean differences differ from model 1 as expected from the different modeling for roughness and foam; however the standard deviation of the differences is very similar to model 1 .

\section{SSS retrieved with model 3 (WISE model)}

The retrieved SSS is as good as with models 1 and 2 up to $10 \mathrm{~m} \cdot \mathrm{s}^{-1}$. Above $11 \mathrm{~m} \cdot \mathrm{s}^{-1}$ the retrieved SMOS SSS is systematically too low and lower than the one obtained with model 1 (Table 4 and Fig. 8). The number of successful retrievals is less than with the other models (between 10 to 14 $\%$ less retrieved SSS) (Table 4).

\section{SSS retrieved using PALS (2010) roughness model}

Using [30] empirical model, SSS bias is strongly dependent on wind speed: it increases with wind speed up to $7 \mathrm{~m} / \mathrm{s}$, remains constant between 7 and $13 \mathrm{~m} / \mathrm{s}$ and decreases above $13 \mathrm{~m} / \mathrm{s}$ (Fig. 9). The bias is slightly lower than with models 1 and 2 between 13 and $18 \mathrm{~m} / \mathrm{s}$. At a given wind speed, the difference between the Southern Pacific and the tropical Pacific is much stronger than with the three other models. The statistics of these comparisons are reported in Table 5. The bias and the standard deviation of the differences are worse than the ones obtained with the three other models.

\section{DISCUSSION AND CONCLUSION}

This study aims at validating SMOS SSS retrieved during the month of August 2010 using the method described in [11][25] that has been implemented into the European Space Agency SMOS processing.

Biases of several pss appear close to land and ice and depend on the orientation of the coast with respect to the orbit. In a preparatory study, [36] estimated that the bias due to the land vicinity on SMOS SSS averaged over 10days should be less than $0.2 \mathrm{pss}$ at distances greater than $47 \mathrm{~km}$ from the coast. With a different approach that takes into account measured antenna patterns for each antenna and all instrument errors, and that uses a land-sea decomposition technique (not implemented in the SMOS Data Processing Groung Segment (DPGS)) described in [38] to significantly reduce the effect of the coastlines, [37] found a significant influence of the coast up to $300 \mathrm{~km}$ from the coast. In this first version of SMOS SSS, we found influence of the coast much further, up to about $1000 \mathrm{~km}$ from the coast. The origin of these biases (problem in image reconstruction and/or in antennas characterization) is under study by SMOS level 1 teams and is expected to be significantly reduced in future versions of the level 1 processor. As a consequence, in that paper, we focus only on regions further than $1000 \mathrm{~km}$ from the coast.

We also observe biases between ascending and descending 
orbits. Several reasons for these biases have been identified since this first version of SMOS sea surface salinity has been delivered (J. Tenerelli, M. Martin Neira, pers. comm. 2011): errors in the implementation of the sun correction in the image reconstruction procedure introduce long and short term drifts in the reconstructed brightness temperatures; the variation of the antennas losses with physical temperature along the orbit and along the year introduce some biases too. Corrections for these biases are under study [39]. In addition, strong galactic noise scattered by the sea surface in the direction of SMOS antenna in August over descending orbits is suspected to be inaccurately accounted for. Hence, it is hoped that in future studies, these systematic SSS biases will be much reduced.

In order to minimize the effects of these systematic biases, as our aim is to make a preliminary estimate of the precision that should be achievable on SMOS SSS once instrument calibration, image reconstruction algorithms and forward models will better fit SMOS measurements, we concentrate our study on ascending orbits and on four regions far from land and ice. The two regions in the Southern Ocean are characterized by very variable wind speed conditions, relatively stable SSS in two different SSS and SST ranges. The subtropical Atlantic Ocean, a region with strong evaporation, is characterized by very salty waters (37 pss) and stable SSS contrary to the tropical Pacific Ocean, a very rainy region, characterized by a large variability of the SSS (0.6 pss).

The radiative transfer models we have tested have been developed independently of SMOS data; this ensures that we do not introduce indirect instrumental flaws in the forward modelling. Nevertheless, the application of an OTT may introduce indirect correlations between forward models and OTT-calibrated SMOS measurements. On the other hand, given the large biases in TB (several $\mathrm{K}$ ) observed to be dependent on the location in the field of view (i.e. very variable with incidence angle), it was not meaningful to perform SSS retrieval without any correction for these systematic biases and the OTT method has been developed as a provisional better-than-nothing method. The way we compute the OTT implies that we implicitly correct for a mean bias between each forward modelled TB and SMOS measurement corresponding to average geophysical conditions encountered on the orbit used to derive the OTT (on the orbit of 5 August, the mean (std) SST is $20.1(6.2)^{\circ} \mathrm{C}$, the mean (std) SSS is $35.0(0.8)$ pss and mean (std) wind speed is $8.1(2.3) \mathrm{m} \mathrm{s}^{-}$ $\left.{ }^{1}\right)$. Hence, when analysing the results presented in this paper, one should look more at the relative variations of the retrieved SSS than at its mean value that depends on the geophysical conditions used for the OTT computation. It is hoped that future research on SMOS data will allow evaluating a correction independent of any sea-surface geophysical parameter. If no other method appears applicable for avoiding an OTT computation, refinements about the statistical distribution of the geophysical parameters to be used for the OTT computation could help improving the mean bias removal but won't allow validating forward models in absolute value.

The global distribution of SMOS SSS is very encouraging; in particular, SSS anomalies in tropical regions seen by ARGO floats also appear on SMOS SSS. Nevertheless the fresh SSS anomaly around $10^{\circ} \mathrm{N}$ in the Northern Pacific is fresher by 0.2 pss on SMOS SSS than on ARGO SSS. The origin of this fresh SMOS anomaly remains uncertain. Since it appears whatever the ECMWF wind speed at the SMOS time is, it is unlikely to be an effect of vertical stratification on SMOS SSS (surface fresh water anomalies are expected to mix with surrounding water when the wind speed increases). We looked whether an imperfect modelling of the sea water permittivity could lead to such a bias by testing the [40] and [41] permittivity models. The differences of the TBs simulated with the two models with respect to Klein and Swift model (Fig. 10) are non negligible ( -0.3 to $-1 \mathrm{~K}$ when using [40] and 0.2 to $0.8 \mathrm{~K}$ when using [41] depending on the incidence angle and on the regional salinity). However, whatever the permittivity model is used the differences are very similar for the two zones of the Pacific Ocean and the part of the orbit chosen to estimate the systematic bias in the FOV (not shown). Hence, the correction for the systematic bias between the SMOS measurements and the modelled TBs we apply is expected to remove most of the bias and none of the permittivity models we tested may explain the fresh water anomaly we observe around $10^{\circ} \mathrm{N}$ in the tropical Pacific Ocean. In the Southern Indian Ocean, the differences in TB obtained with [40] are similar to the ones obtained in the Pacific Ocean whereas [41] suggests that TB calibrated using Klein and Swift model may be too high by about $0.1 \mathrm{~K}$. If the modelled TB is too high, the retrieval process will adjust the geophysical parameters so as to get modelled TB closer to the measured TB. In order to decrease the modelled TB by about $0.1 \mathrm{~K}$, it will increase the SSS in the Southern Indian Ocean by about 0.2-0.3 pss: this is much larger than the biases we observe. Larger differences on the TBs appear in the subtropical Atlantic Ocean with respect to the Pacific Ocean; [40] suggests that TBs calibrated using Klein and Swift model may be too low by $\sim 0.2 \mathrm{~K}$ whereas [41] suggests that they may be too high by $\sim 0.4 \mathrm{~K}$ (Fig. 10). The comparison with ARGO SSS indicates a possible slight positive SSS bias in the tropical Atlantic with respect to the Pacific Ocean, this bias varying from 0 (roughness model 1 ,centered swath, wind speed between 3 and $12 \mathrm{~m} \cdot \mathrm{s}^{-1}$ ) and 0.4 pss (roughness model 3 , centred swath, wind speed between 3 and $12 \mathrm{~m} . \mathrm{s}^{-1}$ ). The latter is consistent with an overestimation of the TBs calibrated using the Klein and Swift model of 0.1$0.2 \mathrm{~K}$ which is in the same direction but smaller by more than a factor 2 to what suggests model [41]. Hence none of the permittivity models tested resolves the SSS biases we observe in the various regions.

The bias on the SSS retrieved with model 1 implemented in the ESA processor is relatively constant between 3 and $12 \mathrm{~m} . \mathrm{s}^{-}$ 1 , about 0.1 pss in each region except in the tropical Pacific where it varies between -0.1 and 0.1 pss; the one on SSS retrieved with model 2 is similar to model 1 between 3 and 12 
$\mathrm{m} . \mathrm{s}^{-1}$ and remains less than 0.5 pss between 12 and $15 \mathrm{~m} . \mathrm{s}^{-1}$; the bias on the SSS retrieved with model 3 in each region is relatively in the range 3 to $10 \mathrm{~m} . \mathrm{s}^{-1}$, between 0 . and 0.2 pss in each region except in the subtropical Atlantic where it reaches 0.4 pss. At wind speed higher than $12 \mathrm{~m} . \mathrm{s}^{-1}$ (respectively 10 $\mathrm{m} . \mathrm{s}^{-1}$ ), model 1 (respectively model 3 ) underestimates the SSS (indicating that they underestimate the wind speed effect on TB) and above $15 \mathrm{~m} . \mathrm{s}^{-1}$ model 2 overestimates the SSS (indicating that it overestimates the wind effect on TB). The standard deviation of the SSS difference are very similar with the three models in the various regions, although they do not use the same prior information for describing sea surface roughness: model 1 uses wind components from ECMWF atmospheric model, model 2 uses friction velocity and wave age from ECMWF wave model, model 3 uses wind speed and significant wave height from ECMWF atmospheric model. This is probably because the main uncertainty remains the influence of roughness and foam on TB. When using the [30] model which dependence with wind speed is linear and stronger at moderate wind speed than the one predicted with models 1 and 2, the SSS bias is very dependent on the wind speed itself; this dependency is stronger in the Southern Ocean (cold region) than in the tropics (warm region). Once SMOS data will have achieved a better maturity, future studies should confirm that a linear dependence of TB at moderate to high with wind speed is unlikely, as suggested by the large biases observed with the PALS parameterization that is linear over the whole wind speed range, and by the SSS underestimate at high wind speed with model 1 and model 3 whereas these models are almost linear above $5 \mathrm{~m} . \mathrm{s}^{-1}$. The need for a non linear TB-wind speed dependence between moderate and high wind speed suggests that the effect of foam cannot be completely neglected. It is expected that a better agreement will be found with a wind speed dependency intermediate between model 1 and model 2

At low wind speed, the SMOS minus ARGO SSS differences are often higher in absolute value and more different from one region to another than at moderate wind speed. This is likely because the relationship between the sea surface emissivity and the local wind speed is weaker at low than at moderate wind speed as it is highly dependent on other parameters, e.g. on the history of the wind. In case of models 1 and 2, the dependency of TB to the wind speed has a larger slope at low wind speed than at moderate wind speed thus enhancing the impact of an error on retrieved wind speed onto retrieved SSS.

Contrary to models 1 and 2 that simulate a small (but not negligible when dealing with SSS retrieval) dependency of the wind induced TB with the SST (Fig. 11), [30] parameterization estimate the wind effect on TB independently of the SST. This could introduce part of the regional bias seen with PALS model but since such a bias is not seen on model 3 which also estimates the wind effect on TB independently of the SST, the effect of SST on wind induced TB will have to be checked once satellite L-band data will have improved.
After averaging SMOS SSS (retrieved over the whole swath) over $100 \mathrm{~km}$ and 10 days and keeping only wind speeds between 3 and $12 \mathrm{~m} . \mathrm{s}^{-1}$ (which represent more than two thirds of the measurements in the regions under study), the standard deviation (the $95 \%$ confidence interval is indicated between parenthesis) between ARGO and SMOS SSS far from land is $0.33(0.06)$ pss in the Southern Indian Ocean, 0.49 (0.05) pss in the Southern Pacific Ocean and $0.3(0.05)$ pss in the subtropical Atlantic Ocean. These values are larger than the ones anticipated from various SMOS simulations before launch (e.g. [35], [37]). The one in the tropical Pacific Ocean, $0.39(0.04)$ pss, is larger than the one in the Southern Indian Ocean and in the subtropical Atlantic Ocean. This cannot be explained by the number of measurements that enters in the average over $100 \mathrm{~km}-10$ days as for wind speeds between 3 and $12 \mathrm{~m} . \mathrm{s}^{-1}$, the mean number of SMOS measurements averaged around one ARGO float is not very different in the three regions (129 in the tropical Pacific Ocean,138 in the Southern Indian Ocean and 117 in the subtropical Atlantic Ocean), nor by the sensitivity of the radiometric signal to the $\mathrm{SST}$ as the SST is colder $\left(14.8^{\circ} \mathrm{C}\right)$ in the Southern Indian Ocean than in the two other regions $\left(26.4^{\circ} \mathrm{C}\right.$ and $\left.27.7^{\circ} \mathrm{C}\right)$. This is likely due to the very high variability of the SSS in this rainy tropical region. Using the full swath data, the averaging process decreases $\sigma$ by a factor $\sim 2.5$ in the tropical Pacific Ocean whereas it decreases by a factor $\sim 3$ in the three other regions (Fig. 6). This suggests that the SMOS SSS - ARGO SSS differences may be more systematic (not reduced in the averaging process) in the tropical Pacific Ocean than in the other regions. [42] found that the reduction of the error is expected to be larger in regions with high variability; hence the smaller variability of the wind in tropical region with respect to high latitude regions may explain some difference but not the different error reduction between sub-tropical Atlantic Ocean and tropical Pacific Ocean. The mean SSS in the tropical Pacific Ocean is fresher by 0.2 pss with respect to ARGO floats SSS contrary to the other regions where it is slightly saltier. Whether this could be due in this rainy region to fresher SSS in the first centimetre of the sea surface sensed by SMOS with respect to ARGO measurements sampled at several meters depth will need to be further checked with reprocessed data (once image reconstruction and calibration issues have been completely solved). Future studies should also consider possible stratifications close to the sea surface as measured by surface drifters measuring SSS at typically $50 \mathrm{~cm}$ in rainy regions.

If one assumes that in the future, image reconstruction and calibration issues, galactic noise correction and wind speed effect above $12 \mathrm{~m} . \mathrm{s}^{-1}$ may be more accurately taken into account, one could merge ascending and descending orbits and use SSS retrieved over the whole wind speed range, increasing the number of measurements by a factor 2.1 to 2.8 so that we can expect, except in rainy regions, to achieve a precision on an SSS averaged over $100 \mathrm{~km}$ and 10 days between 0.2 and 0.3 pss and on the order of $0.1-0.15$ pss on an SSS averaged 
over $200 \mathrm{~km} \times 200 \mathrm{~km}$ and 10 days (under the assumption of random noise which is not true in rainy region).

This paper has been limited to a one month study because temporal biases observed over long periods in SMOS reconstructed brightness temperatures need to be corrected before any long time study could be envisaged.

We show that with SMOS technology, the GODAE (Global Ocean Data Assimilation Experiment) requirement (to have SSS with an accuracy of 0.1 in boxes of $200 \mathrm{~km} \times 200 \mathrm{~km}$ in 10-days average) is not out of reach provided that systematic spatial image reconstruction errors and temporal drifts in SMOS brightness temperatures, roughness and foam emissivity modelling at high wind speed and scattering of strong galactic noise by the sea surface are handled correctly.

\section{ACKNOWLEDGMENT}

We thank two anonymous reviewers for their constructive remarks and suggestions. We are indebted to the other participants of the ESL team (CLS and ACRI-st) and SMOS level 1 and level 2 Soil Moisture teams for very helpful interactions. We are very grateful to G. Reverdin and S. Arnault for their constructive comments about this work and for their advices about salinity measurements and ARGO profilers. We also thank $\mathrm{S}$. Yueh for providing some parameterizations of the azimuthal dependency of his new experimental model. The ARGO data were collected and made freely available by the International Argo Project and the national programmes that contribute to it (http://www.argo.net). Argo is a pilot programme of the Global Ocean Observing System.

\section{REFERENCES}

[1] GCOS, Progress Report on the Implementation of the Global Observing System for Climate in Support of the UNFCCC 2004-2008, 2009 , GCOS-129 (WMO-TD/No. 1489, GOOS-173, GTOS-70), available on http://gosic.org/ios/GCOS-main-page.htm.

[2] GCOS, Implementation Plan for the Global Observing System for Climate in Support of the UNFCCC (2010 Update), 2010, GCOS-138, (GOOS-184, GTOS-76, WMO-TD/No. 1523), available on http://gosic.org/ios/GCOS-main-page.htm.

[3] Lagerloef, G., Boutin, J., Chao, Y., Delcroix, T., Font, J., Niiler, P., Reul, N., Riser, S., Schmitt, R., Stammer, D. and Wentz, F., "Resolving the Global Surface Salinity Field and Variations by Blending Satellite and In Situ Observations" in Proceedings of OceanObs'09: Sustained Ocean Observations and Information for Society (Vol. 2), Venice, Italy, 21-25 September 2009, Hall, J., Harrison, D.E. \& Stammer, D., Eds., ESA Publication WPP-306, doi:10.5270/OceanObs09.cwp.51, 2010.

[4] Lerner. R.M. and J.P. Hollinger, "Analysis of $1.4 \mathrm{GHz}$ radiometric measurements from Skylab" Remote Sens. Environ., 6, 251-269, 1977.

[5] Lagerloef, G., C. Swift and D. LeVine, "Sea surface salinity: The next remote sensing challenge", Oceanography, 8, 44-50, 1995.

[6] Unesco, 1981: The Practical Salinity Scale 1978 and the International Equation of State of Seawater 1980. Unesco technical papers in marine science $36,25 \mathrm{pp}$.

[7] Font, J. et al., SMOS first data analysis for sea surface salinity determination, accepted in Int. Journal Rem. Sens., 2011.

[8] Kerr, Y., P. Waldteufel, J. P. Wigneron, J. M. Martinuzzi, J. Font, and M. Berger, 2001: Soil moisture retrieval from space: The soil moisture and ocean salinity mission (SMOS). IEEE Trans. Geosci. Remote Sens., 39, 1729-1735.

[9] J. Font, A. Camps, A. Borges, M. Martín-Neira, J. Boutin, N. Reul, Y.
Kerr, A. Hahne, and S. Mecklenburg, "SMOS: The challenging measurement of sea surface salinity from space," Proceedings of the IEEE, vol. 98 , no. 5 , pp. 649-66, May 2010.

[10] P. Waldteufel, J. Boutin, and Y. Kerr, "Selecting an optimal configuration for the Soil Moisture and Ocean Salinity mission," Radio Sci., vol. 38, pp. 8051, 10.1029/2002RS002744, 2003.

[11] S. Zine, J. Boutin, J. Font, N. Reul, P. Waldteufel, C. Gabarró, J. Tenerelli, F. Petitcolin, J. L. Vergely, M. Talone, and S. Delwart, "Overview of the SMOS sea surface salinity prototype processor," IEEE T. Geosci. Remote, vol. 46, pp. 621-645, 2008.

[12] D. Marquardt, "An algorithm for least-squares estimation of non-linear parameters," J. Soc. Ind. Appl. Math., vol. 11, pp. 431-441, 1963.

[13] H. J. Liebe, G. A. Hufford, and M. G. Cotton, "Propagation modeling of moist air and suspended water/ice particles at frequencies below $1000 \mathrm{GHz}$," presented at the AGARD 52nd Specialists' Meeting Electromagnetic Wave Propagation Panel, Palma de Mallorca, Spain, 1993.

[14] J. E. Tenerelli, N. Reul, A. A. Mouche, and B. Chapron, "Earthviewing L-band radiometer sensing of sea surface scattered celestial sky radiation - Part I: General characteristics," IEEE Trans. Geosci. Remote Sens., vol. 46, no. 3, pp. 659-674, Mar. 2008.

[15] N. Reul, J. Tenerelli, N. Floury, and B. Chapron, "Earth-viewing Lband radiometer sensing of sea surface scattered celestial sky radiation-Part II: Application to SMOS," IEEE Trans. Geosci. Remote Sens., vol. 46, no. 3, pp. 675-688, Mar. 2008.

[16] L. A. Klein and C. T. Swift, "An improved model for the dielectric constant of sea water at microwave frequencies," IEEE Trans. Antennas Propag., vol. AP-25, no. 1, pp. 104-111, Jan. 1977.

[17] S. L. Durden and J. F. Vesecky, "A physical radar cross-section model for a wind-driven sea with swell," IEEE J. Ocean. Eng., vol. OE-10, no. 4, pp. 445-451, Oct. 1985.

[18] S. H. Yueh, "Modeling of wind direction signals in polarimetric sea surface brightness temperatures," IEEE Trans. Geosci. Remote Sens., vol. 35, no. 6, pp. 1400-1418, Nov. 1997.

[19] E. P. Dinnat, J. Boutin, G. Caudal, and J. Etcheto, "Issues concerning the sea emissivity modeling at L band for retrieving surface salinity," Radio Sci., vol. 38, no. 4, 8060, 2003, DOI:10.1029/2002RS002637.

[20] V. G. Irisov, "Small-slope expansion for thermal and reflected radiation from a rough surface," Waves Random Media, vol. 7, no. 1, pp. 1-10, Jan. 1997.

[21] J. T. Johnson and M. Zhang, "Theoretical study of the small slope approximation for ocean polarimetric thermal emission," IEEE Trans. Geosci.Remote Sens., vol. 37, no. 5, pp. 2305-2316, Sep. 1999.

[22] V. N. Kudryavtsev, V. K. Makin, and B. Chapron, "Coupled sea surfaceatmosphere model—Part 2: Spectrum of short wind waves," J. Geophys. Res., vol. 104, no. C4, pp. 7625-7639, 1999.

[23] N. Reul and B. Chapron, "A model of sea foam thickness distribution for passive microwave remote sensing applications," J. Geophys. Res., vol. 108, no. C10, 3321, 2003, DOI: 10.1029/2003JC001887.

[24] A. Camps, M. Vall-llosera, R. Villarino, N. Reul, B. Chapron, I. Corbella, N. Duffo, F. Torres, J. J. Miranda, R. Sabia, A. Monerris, and R. Rodríguez, "The emissivity of foam-covered water surface at Lband: Theoretical modeling and experimental results from the FROG 2003 field experiment," IEEE Trans. Geosci. Remote Sens., vol. 43, no. 5, pp. 925-937, May 2005.

[25] J. Font, J. Boutin, N. Reul, P. Waldteufel, C. Gabarró, S. Zine, and J. Tenerelli, SMOS Sea Surface Salinity Level 2 Algorithm Theoretical Baseline Document-Issue 2, European Space Agency ESTEC Contract 18933/05/NL/FF, 2007.

[26] J. Etcheto, E. P. Dinnat, J. Boutin, A. Camps, J. Miller, S. Contardo, J. Wesson, J. Font, and D. G. Long, "Wind speed effect on L-band brightness temperatures inferred from EuroSTARRS and WISE 2001 field experiments," IEEE Trans. Geosci. Remote Sens., vol. 42, no. 10, pp. 2206-2213, Oct. 2004.

[27] A. Camps, J. Font, M. Vall-llosera, C. Gabarró, I. Corbella, N. Duffo,F. Torres, S. Blanch, A. Aguasca, R. Villarino, L. Enrique, J. J. Miranda,J. Arenas, A. Juliá, J. Etcheto, V. Caselles, A. Weill, J. Boutin,S. Contardo, R. Niclós, R. Rivas, S. C. Reising, P. Wursteisen,M. Berger, and M. Martín-Neira, "The WISE 2000 and 2001 field experiments in support of the SMOS mission: Sea surface Lband brightness temperature observations and their application to sea surface salinity retrieval,” IEEE Trans. Geosci. Remote Sens., vol. 42, 
no. 4, pp. 804-823, Apr. 2004.

[28] C. Gabarró, J. Font, A. Camps, M. Vall-llosera, and A. Juliá, “A new empirical model of sea surface microwave emissivity for salinity remote sensing," Geophys. Res. Lett., vol. 31, no. 1, pp. L01309-1L01309-5, 2004, DOI: 10.1029/2003GL018964.

[29] C. Gabarró, J. Font, J. L. Miller, A. Camps, D. Burrage, J. Wesson, and A. R. Piola, "The use of a semi-empirical emissivity model for a rough estimation of sea surface salinity from an airborne microwave radiometer," Sci. Mar, 72(2): 329-336, 2008, ISSN: 0214-8358.

[30] S.H. Yueh, S.J. Dinardo, A.G. Fore, F.K. Li, "Observations and Modeling of Ocean Surface Winds", IEEE Trans. Geosci. Remote Sens., vol. 48, no. 8, pp. 3087-3100, Aug. 2010, doi:10.1109/TGRS.2010.2045002.

[31] X. Yin, J. Boutin, P. Spurgeon, First assessment of SMOS measurements over open ocean: part I Pacific Ocean, submitted to this issue, 2011.

[32] J. I. Antonov, R. A. Locarnini, T. P. Boyer, A. V. Mishonov, and H. E. Garcia, 2006. World Ocean Atlas 2005, Volume 2: Salinity. S. Levitus, Ed. NOAA Atlas NESDIS 62, U.S. Government Printing Office, Washington, D.C., $182 \mathrm{pp}$.

[33] B. Bengoa and M. Zapata, SMOS Level 2 and Auxiliary Data Products Specifications, Indra, SO-TN-IDR-GS-0006, 25-Sep-2009.

[34] Yin, X., J. Boutin, P. Spurgeon, J.L. Vergely, P. Waldteufel, First analysis of SMOS sea surface salinity, Proceedings of the ESA Living Planet Symposium, Bergen, Norway, 28 June - 2 July 2010 (ESA SP686, December 2010), ISBN 978-92-9221-250-6

[35] Boutin, J., P. Waldteufel, N. Martin, G. Caudal, and E. Dinnat, Surface salinity retrieved from SMOS measurements over global ocean: imprecisions due to surface roughness and temperature uncertainties, Journal of Atmospheric and Oceanic Technology, 21, 1432-1447, 2004

[36] S. Zine, J. Boutin, P. Waldteufel, J. L. Vergely, and P. Lazure: "Issues about retrieving sea surface salinity in coastal areas from SMOS data". IEEE Transactions on Geoscience and Remote Sensing, 45, 10.1109/TGRS.2007.894934, 2007.

[37] Talone M., A. Camps, B. Mourre, R. Sabia, M. Vall•llossera, J. Gourrion, C. Gabarró, and J. Font, Simulated SMOS Level 2 And 3 Products: The Effect of Introducing Argo Data in the Processing Chain and its Impact on the Error Induced by the Vicinity of the Coast, IEEE Transactions on Geoscience and Remote Sensing, Vol. 47(9), pp. 30413050, September 2009

[38] A. Camps, M. Vall-Llossera, I. Corbella, N. Duffo, and F. Torres, "Improved image reconstruction algorithms for aperture synthesis radiometers," IEEE Trans. Geosci. Remote Sens., vol. 46, no. 1, pp. 146-158, Jan. 2008.

[39] R. Oliva, M. Martin-Neira, I. Corbella, F. Torres, J. Kainulainen, J. E. Tenerelli, F. Cabot, and F. Martin-Porqueras. SMOS calibration and instrument performance after one year in orbit. IEEE Trans. Geosci. and Remote Sens., 2011. Submitted.

[40] Lang, R.H.; Yi Jin; Utku, C.; Shuo Gu; Le Vine, D.; , "A new model function for the permittivity of seawater at $1.413 \mathrm{GHZ}, 2010$ 11th Specialist Meeting on Microwave Radiometry and Remote Sensing of the Environment (MicroRad), p.121-123,

10.1109/MICRORAD.2010.5559576, 1-4 March 2010

[41] Blanch, S.; Aguasca, A.; Seawater dielectric permittivity model from measurements at L band, IGARSS '04. Proceedings, Volume: 2, pp. 1362 - 1365, DOI: 10.1109/IGARSS.2004.1368671.

[42] A. Camps, M. Vall.llossera, L. Batres, N. Duffo, F. Torres, I. Corbella, Retrieving Sea Surface Salinity With Multi-Angular L-band Brightness Temperatures: Improvement By Spatio-Temporal Averaging, Radio Science, Vol. 40, RS2003, doi:10.1029/2004RS003040, March 2005.

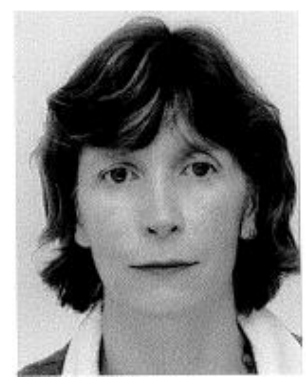

Jacqueline Boutin received the Ph.D. degree in physical methods in remote sensing from the University Paris VII, Paris, France, in 1990.

She is currently a Research Scientist at the Centre National de la Recherche Scientifique (CNRS) in the Laboratoire d'Océanographie et du Climat-Expérimentation et Approches Numériques (LOCEAN), Paris. She has widely studied the validity of remotely sensed wind speeds and the ocean/atmosphere exchange of
$\mathrm{CO} 2$ at large scale using both satellite (wind speeds, sea surface temperature, and ocean color) and in situ data (in particular, carbon-interface oceanatmosphere autonomous drifters, CARIOCA). Since 1999, she has been involved in the preparation of the SMOS mission. She participated in the development of an L-band sea surface emissivity model and in several airborne campaigns (WISE and Eurostarrs). She is a member of the European Space Agency Expert Support Laboratories that define and validate the processing of SMOS Level 2 measurements for the retrieval of sea surface salinity.

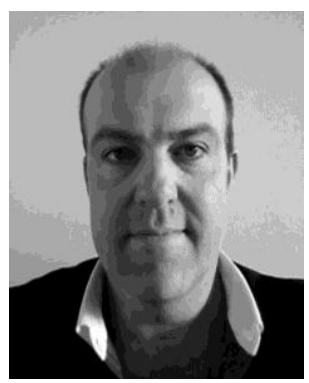

Nicolas Martin is a research engineer working at Centre National de la Recherche Scientfiique in the Laboratoire d'Océnographie et du Climat Expérimentations et Approches Numériques (LOCEAN). He received the $\mathrm{Ph}$. D degree in Robotics and Vision from the University of Bordeaux I in 1995. Since 1999, he is working in data processing of measurements made by surface salinity drifters and validation of SMOS measurements.

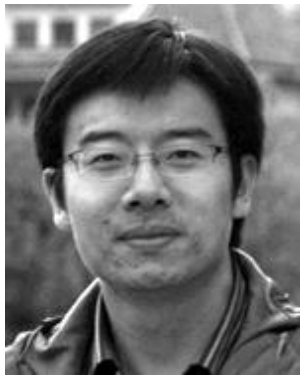

Xiaobin Yin received the B.Sc. and Ph.D. degrees in ocean science and physical oceanography from the Ocean University of China, Qingdao, China, in 2003 and 2007, respectively. He has studied remote sensing of sea surface salinity and sea surface wind with multi-frequency microwave radiometer.

Since 2009, he has been with the Laboratoire d'Océanographie et du Climat-Expérimentation et Approches Numériques (LOCEAN), Paris, France, working on the SMOS mission. He is now involved in validation of L-band radiometric measurements and improvement of Level 2 ocean salinity retrieval algorithms.

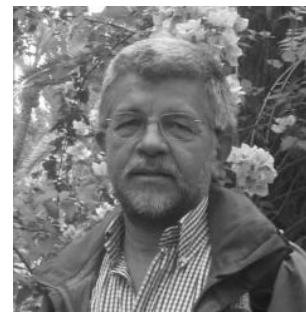

Dr. Jordi Font obtained a B.Sc. (1973) and a Ph.D. (1986) in Physics in the University of Barcelona. He is Research Professor at the Physical Oceanography Department of the Institut de Ciències del Mar (Spanish Research Council, CSIC), Barcelona. Member of several international societies and committees. Participant in 42 oceanographic campaigns. Author or co-author of 300 communications to scientific symposia and 260 published papers (75 in SCI journals). Adviser of $9 \mathrm{PhD}$ thesis. PI in several Spanish and European research contracts. Main research interests: Ocean remote sensing: determination of sea surface salinity by microwave radiometry. Physical oceanography of the Mediterranean Sea: water masses, circulation and climate change. Ocean circulation: operational measurements of ocean currents, technological improvements. Mesoscale dynamics: fronts, eddies, topographic interactions, physical-biological processes coupling. At present he is Co-Lead Investigator for ocean salinity in the European Space Agency Soil Moisture and Ocean Salinity (SMOS) mission. Until May 2010 he was Chairman of the Ocean Physics and Climate Committee of the International Commission for the Scientific Exploration of the Mediterranean Sea CIESM. He received the National Arts Award 2011 of the Catalan Government in the category of Thought and Scientific Culture.

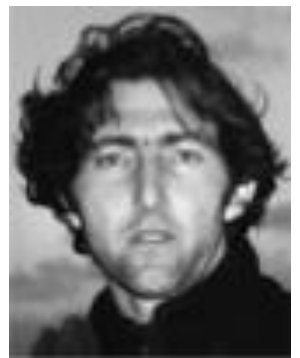

Nicolas Reul received the B.S. degree in marine science engineering from Toulon University, La Garde, France, in 1993, and the Ph.D. degree in physics (fluid mechanics) from the University of Aix-Marseille II, Marseille, France, in 1998. 
From 1999 to 2001, he worked as a Postdoctoral Researcher with the Applied Marine Physics Department, Rosenstiel School of Marine and Atmospheric Science, University of Miami, Coral Gables, FL. Since 2001, he has been a Research Scientist with the Spatial Oceanography Group, Institut Français de Recherche pour l'Exploitation de la Mer, Plouzané, France, where he is responsible for the activities concerning the SMOS satellite mission. The focus of his research program is to improve the understanding of the physical processes at air-sea interface and passive/active remote sensing of the ocean surface. He has experience in applied mathematics, physical oceanography, electromagnetic wave theory, and its application to ocean remote sensing. He is currently a member of the European Space Agency/SMOS Quality Working Group.

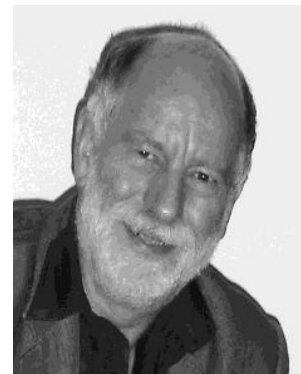

Paul Spurgeon is Project Manager at ARGANS in Plymouth, UK, a company specializing in Earth Observation research and development. He is a scientist and software engineer, and leads an international team of Expert Support Laboratories designing, implementing and validating the European Space Agency SMOS Level 2 Ocean Salinity processor, which generates SMOS data in near real-time. $\mathrm{He}$ is responsible for a web-site (www.argans.co.uk/smos) monitoring global and regional sea surface salinity products. 
TABLE 1

STATISTICS OF SMOS SSS COLOCATED WITH ARGO AT +/-5DAYS AND +/-50KM DURING AUGUST; SMOS SSS ARE FROM ASCENDING ORBITS AND ARE NOT AVERAGED.

\begin{tabular}{|c|c|c|c|c|c|c|c|c|}
\hline Zone & \multicolumn{2}{|c|}{ South Indian } & \multicolumn{2}{|c|}{ South Pacific } & \multicolumn{2}{|c|}{ N. Trop. Pac } & \multicolumn{2}{|c|}{ N. Subtrop. Atl. } \\
\hline Latitude/ & \multicolumn{2}{|c|}{$40 \mathrm{~S}-30 \mathrm{~S} /$} & \multicolumn{2}{|c|}{$50 \mathrm{~S}-40 \mathrm{~S} /$} & \multicolumn{2}{|c|}{$5 \mathrm{~N}-15 \mathrm{~N} /$} & \multicolumn{2}{|c|}{$15 \mathrm{~N}-30 \mathrm{~N} /$} \\
\hline Longitude & \multicolumn{2}{|c|}{$70 \mathrm{E}-90 \mathrm{E}$} & \multicolumn{2}{|c|}{$180 \mathrm{~W}-100 \mathrm{~W}$} & \multicolumn{2}{|c|}{ 180W-110W } & \multicolumn{2}{|c|}{$45 \mathrm{~W}-30 \mathrm{~W}$} \\
\hline Mean SST/Mean SSS & \multicolumn{2}{|c|}{$14,8^{\circ} \mathrm{C} / 35,4$} & \multicolumn{2}{|c|}{$9,8^{\circ} \mathrm{C} / 34,4$} & \multicolumn{2}{|c|}{$27,7^{\circ} \mathrm{C} / 34,1$} & \multicolumn{2}{|c|}{$26,4^{\circ} \mathrm{C} / 37,3$} \\
\hline Wind speed range $\left(\mathrm{m} \cdot \mathrm{s}^{-1}\right)$ & All & $3-12$ & All & $3-12$ & All & $3-12$ & All & $3-12$ \\
\hline \multicolumn{9}{|l|}{ Full swath } \\
\hline $\mathrm{N}$ & 7927 & 6558 & 32461 & 22927 & 32662 & 30814 & 7590 & 6939 \\
\hline median(SSSsmos-SSSargo) & 0,16 & 0,24 & 0,01 & 0,18 & $-0,11$ & $-0,09$ & 0,22 & 0,17 \\
\hline$\sigma($ SSSsmos-SSSargo $)$ & 1,26 & 1,19 & 1,65 & 1,51 & 1,02 & 1,02 & 0,89 & 0,9 \\
\hline \multicolumn{9}{|l|}{ Center swath $(+/-300 \mathrm{~km})$} \\
\hline $\mathrm{N}$ & 3719 & 3109 & 16174 & 11677 & 16635 & 15675 & 3913 & 3603 \\
\hline median(SSSsmos-SSSargo) & 0,09 & 0,13 & $-0,09$ & 0,1 & $-0,16$ & $-0,15$ & 0,12 & 0,11 \\
\hline$\sigma($ SSSsmos-SSSargo $)$ & 0,83 & 0,81 & 1,23 & 1,07 & 0,68 & 0,68 & 0,61 & 0,61 \\
\hline
\end{tabular}

TABLE 2

STATISTICS OF SMOS SSS COLOCATED WITH ARGO AT +/-5DAYS AND +/-50KM DURING AUGUST; SMOS SSS ARE FROM ASCENDING ORBITS AND ARE AVERAGED OVER 10 DAYS AND 100KM.

\begin{tabular}{|c|c|c|c|c|c|c|c|c|}
\hline Zone & \multicolumn{2}{|c|}{ South Indian } & \multicolumn{2}{|c|}{ South Pacific } & \multicolumn{2}{|c|}{ N. Trop. Pac } & \multicolumn{2}{|c|}{ N. Subtrop. Atl. } \\
\hline Latitude/ & \multicolumn{2}{|c|}{$40 \mathrm{~S}-30 \mathrm{~S} /$} & \multicolumn{2}{|c|}{$50 \mathrm{~S}-40 \mathrm{~S} /$} & \multicolumn{2}{|c|}{$5 \mathrm{~N}-15 \mathrm{~N} /$} & \multicolumn{2}{|c|}{$15 \mathrm{~N}-30 \mathrm{~N} /$} \\
\hline Longitude & \multicolumn{2}{|c|}{$70 \mathrm{E}-90 \mathrm{E}$} & \multicolumn{2}{|c|}{$180 \mathrm{~W}-100 \mathrm{~W}$} & \multicolumn{2}{|c|}{ 180W-110W } & \multicolumn{2}{|c|}{$45 \mathrm{~W}-30 \mathrm{~W}$} \\
\hline Mean SST/Mean SSS & \multicolumn{2}{|c|}{$14,8^{\circ} \mathrm{C} / 35,4$} & \multicolumn{2}{|c|}{$9,8^{\circ} \mathrm{C} / 34,4$} & \multicolumn{2}{|c|}{$27,7^{\circ} \mathrm{C} / 34,1$} & \multicolumn{2}{|c|}{$26,4^{\circ} \mathrm{C} / 37,3$} \\
\hline Wind speed range $\left(\mathrm{m} \cdot \mathrm{s}^{-1}\right)$ & All & $3-12$ & All & $3-12$ & All & $3-12$ & All & $3-12$ \\
\hline \multicolumn{9}{|l|}{ Full swath } \\
\hline $\mathrm{N}$ & 51 & 51 & 167 & 166 & 238 & 238 & 59 & 59 \\
\hline median(SSSsmos-SSSargo) & 0,14 & 0,22 & $-0,01$ & 0,13 & $-0,17$ & $-0,17$ & 0,13 & 0,09 \\
\hline$\sigma($ SSSsmos-SSSargo $)$ & 0,35 & 0,33 & 0,54 & 0,49 & 0,38 & 0,39 & 0,29 & 0,3 \\
\hline \multicolumn{9}{|l|}{ Center swath $(+/-300 \mathrm{~km})$} \\
\hline $\mathrm{N}$ & 51 & 50 & 167 & 160 & 236 & 236 & 59 & 59 \\
\hline median(SSSsmos-SSSargo) & 0,08 & 0,11 & $-0,03$ & 0,09 & $-0,18$ & $-0,18$ & 0,05 & 0,1 \\
\hline$\sigma($ SSSsmos-SSSargo $)$ & 0,46 & 0,46 & 0,65 & 0,56 & 0,42 & 0,44 & 0,33 & 0,35 \\
\hline
\end{tabular}

TABLE 3

STATISTICS OF SMOS SSS COLOCATED WITH ARGO AT +/-5DAYS AND +/-50KM DURING AUGUST; SMOS SSS ARE RETIEVED WITH MODEL 2 FROM ASCENDING ORBITS AND ARE NOT AVERAGED

\begin{tabular}{|c|c|c|c|c|c|c|c|c|}
\hline Zone & \multicolumn{2}{|c|}{ South Indian } & \multicolumn{2}{|c|}{ South Pacific } & \multicolumn{2}{|c|}{ N. Trop. Pac } & \multicolumn{2}{|c|}{ N. Subtrop. Atl. } \\
\hline Latitude/ & \multicolumn{2}{|c|}{ 40S-30S/ } & \multicolumn{2}{|c|}{$50 \mathrm{~S}-40 \mathrm{~S} /$} & \multicolumn{2}{|c|}{$5 \mathrm{~N}-15 \mathrm{~N} /$} & \multicolumn{2}{|c|}{$15 \mathrm{~N}-30 \mathrm{~N} /$} \\
\hline Longitude & \multicolumn{2}{|c|}{$70 \mathrm{E}-90 \mathrm{E}$} & \multicolumn{2}{|c|}{$180 \mathrm{~W}-100 \mathrm{~W}$} & \multicolumn{2}{|c|}{$180 \mathrm{~W}-110 \mathrm{~W}$} & \multicolumn{2}{|c|}{$45 \mathrm{~W}-30 \mathrm{~W}$} \\
\hline Mean SST/Mean SSS & \multicolumn{2}{|c|}{$14,8^{\circ} \mathrm{C} / 35,4$} & \multicolumn{2}{|c|}{$9,8^{\circ} \mathrm{C} / 34,4$} & \multicolumn{2}{|c|}{$27,7^{\circ} \mathrm{C} / 34,1$} & \multicolumn{2}{|c|}{$26,4^{\circ} \mathrm{C} / 37,3$} \\
\hline Wind speed range $\left(\mathrm{m} \cdot \mathrm{s}^{-1}\right)$ & All & $3-12$ & All & $3-12$ & All & $3-12$ & All & $3-12$ \\
\hline \multicolumn{9}{|l|}{ Full swath } \\
\hline $\mathrm{N}$ & 8763 & 7307 & 31738 & 22586 & 32503 & 30669 & 7946 & 7273 \\
\hline median(SSSsmos-SSSargo) & 0,36 & 0,32 & 0 & $-0,03$ & 0,08 & 0,08 & 0,36 & 0,36 \\
\hline$\sigma($ SSSsmos-SSSargo) & 1,24 & 1,23 & 1,58 & 1,45 & 0,99 & 0,98 & 0,95 & 0,95 \\
\hline \multicolumn{9}{|l|}{ Center swath $(+/-300 \mathrm{~km})$} \\
\hline $\mathrm{N}$ & 4255 & 3550 & 15800 & 11549 & 16558 & 15583 & 3990 & 3671 \\
\hline median(SSSsmos-SSSargo) & 0,28 & 0,26 & $-0,07$ & $-0,09$ & 0,07 & 0,06 & 0,32 & 0,32 \\
\hline$\sigma($ SSSsmos-SSSargo $)$ & 0,81 & 0,81 & 1,21 & 1,04 & 0,67 & 0,67 & 0,6 & 0,59 \\
\hline
\end{tabular}


TABLE 4

STATISTICS OF SMOS SSS COLOCATED WITH ARGO AT +/-5DAYS AND +/-50KM DURING AUGUST; SMOS SSS ARE RETRIEVED WITH MODEL 3 FROM ASCENDING ORBITS AND ARE NOT AVERAGED.

\begin{tabular}{|c|c|c|c|c|c|c|c|c|}
\hline Zone & \multicolumn{2}{|c|}{ South Indian } & \multicolumn{2}{|c|}{ South Pacific } & \multicolumn{2}{|c|}{ N. Trop. Pac } & \multicolumn{2}{|c|}{ N. Subtrop. Atl. } \\
\hline Latitude/ & \multicolumn{2}{|c|}{$40 \mathrm{~S}-30 \mathrm{~S} /$} & \multicolumn{2}{|c|}{$50 \mathrm{~S}-40 \mathrm{~S} /$} & \multicolumn{2}{|c|}{$5 \mathrm{~N}-15 \mathrm{~N} /$} & \multicolumn{2}{|c|}{$15 \mathrm{~N}-30 \mathrm{~N} /$} \\
\hline Longitude & \multicolumn{2}{|c|}{$70 \mathrm{E}-90 \mathrm{E}$} & \multicolumn{2}{|c|}{$180 \mathrm{~W}-100 \mathrm{~W}$} & \multicolumn{2}{|c|}{$180 \mathrm{~W}-110 \mathrm{~W}$} & \multicolumn{2}{|c|}{$45 \mathrm{~W}-30 \mathrm{~W}$} \\
\hline Mean SST/Mean SSS & \multicolumn{2}{|c|}{$14,8^{\circ} \mathrm{C} / 35,4$} & \multicolumn{2}{|c|}{$9,8^{\circ} \mathrm{C} / 34,4$} & \multicolumn{2}{|c|}{$27,7^{\circ} \mathrm{C} / 34,1$} & \multicolumn{2}{|c|}{$26,4^{\circ} \mathrm{C} / 37,3$} \\
\hline Wind speed range $\left(\mathrm{m} \cdot \mathrm{s}^{-1}\right)$ & All & $3-12$ & All & $3-12$ & All & $3-12$ & All & $3-12$ \\
\hline \multicolumn{9}{|l|}{ Full swath } \\
\hline $\mathrm{N}$ & 7667 & 6505 & 27074 & 20175 & 29018 & 27828 & 7262 & 6738 \\
\hline median(SSSsmos-SSSargo) & 0,09 & 0,17 & 0,16 & 0,01 & 0,01 & 0,03 & 0,33 & 0,33 \\
\hline$\sigma($ SSSsmos-SSSargo $)$ & 1,32 & 1,26 & 1,65 & 1,48 & 1,03 & 1,02 & 1,02 & 1,01 \\
\hline \multicolumn{9}{|l|}{ Center swath $(+/-300 \mathrm{~km})$} \\
\hline $\mathrm{N}$ & 3635 & 3076 & 13099 & 10176 & 14263 & 13642 & 3513 & 3291 \\
\hline median(SSSsmos-SSSargo) & 0,11 & 0,16 & 0,14 & 0,03 & 0,12 & 0,13 & 0,41 & 0,39 \\
\hline$\sigma($ SSSsmos-SSSargo $)$ & 0,81 & 0,78 & 1,30 & 1,04 & 0,67 & 0,67 & 0,60 & 0,59 \\
\hline
\end{tabular}

TABLE 5

STATISTICS OF SMOS SSS COLOCATED WITH ARGO AT +/-5DAYS AND +/50KM DURING AUGUST; SMOS SSS ARE RETRIEVED WITH PALS MODEL FROM ASCENDING ORBITS AND ARE NOT AVERAGED.

\begin{tabular}{|c|c|c|c|c|}
\hline Zone & \multicolumn{2}{|c|}{ South Pacific } & \multicolumn{2}{|c|}{ N. Trop. Pac } \\
\hline Latitude/ & \multirow{2}{*}{\multicolumn{2}{|c|}{$\begin{array}{l}\text { 50S-40S/ } \\
180 \mathrm{~W}-100 \mathrm{~W}\end{array}$}} & \multicolumn{2}{|c|}{$5 \mathrm{~N}-15 \mathrm{~N} /$} \\
\hline Longitude & & & $180 \mathrm{~W}-$ & $10 \mathrm{~W}$ \\
\hline Mean SST/Mean SSS & \multicolumn{2}{|c|}{$9,8^{\circ} \mathrm{C} / 34,4$} & \multicolumn{2}{|c|}{$27,7^{\circ} \mathrm{C} / 34,1$} \\
\hline Wind speed range $\left(\mathrm{m} \cdot \mathrm{s}^{-1}\right)$ & All & $3-12$ & All & $3-12$ \\
\hline \multicolumn{5}{|l|}{ Full swath } \\
\hline $\mathrm{N}$ & 32603 & 22915 & 32546 & 30757 \\
\hline median(SSSsmos-SSSargo) & 0,57 & 0,66 & $-0,32$ & $-0,28$ \\
\hline$\sigma$ (SSSsmos-SSSargo) & 1,79 & 1,66 & 1,08 & 1,06 \\
\hline \multicolumn{5}{|l|}{ Center swath $(+/-300 \mathrm{~km})$} \\
\hline $\mathrm{N}$ & 16331 & 11738 & 16571 & 15656 \\
\hline median(SSSsmos-SSSargo) & 0,49 & 0,62 & $-0,38$ & $-0,35$ \\
\hline$\sigma$ (SSSsmos-SSSargo) & 1,48 & 1,34 & 0,74 & 0,71 \\
\hline
\end{tabular}
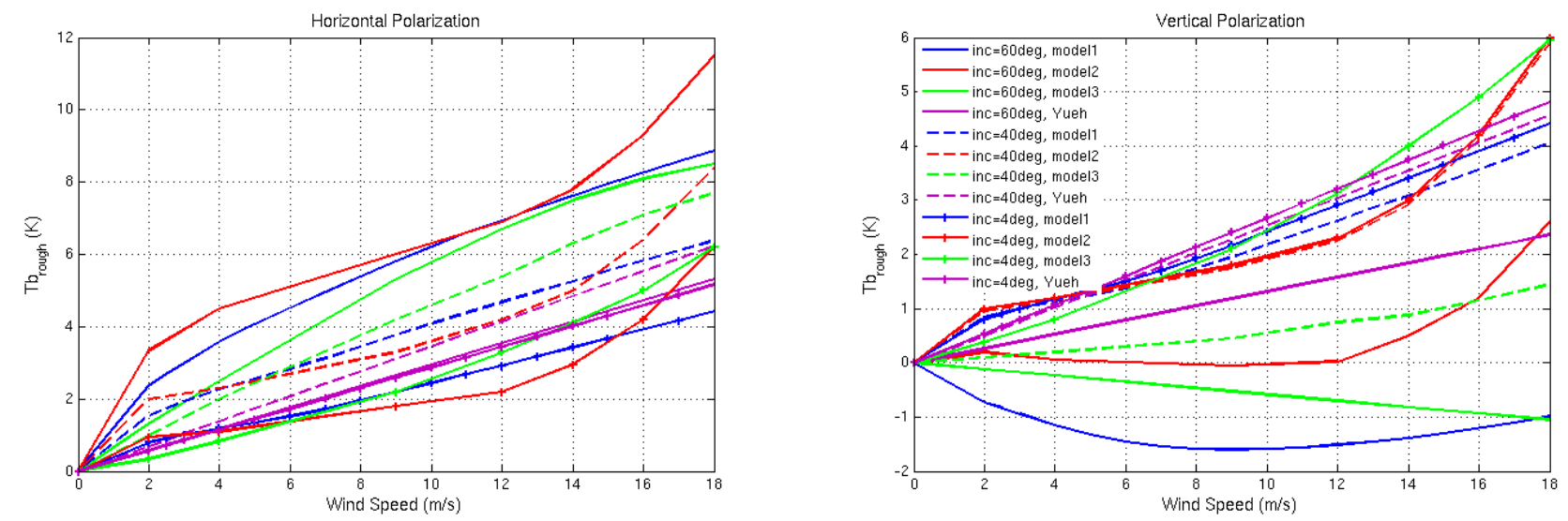

Fig. 1 : Roughness component versus wind speed for different forward models and incidence angles in (left) horizontal and (right) vertical polarizations. Model 1 (blue), model 2 under the assumption of a fully developed sea (red), model 3 (WISE model) assuming a wind speed-significant wave height as in [11] (green) and PALS model (purple). Incidence angles: full lines with crosses: $4^{\circ}$, dashed line: $40^{\circ}$, full line: $60^{\circ}$. 

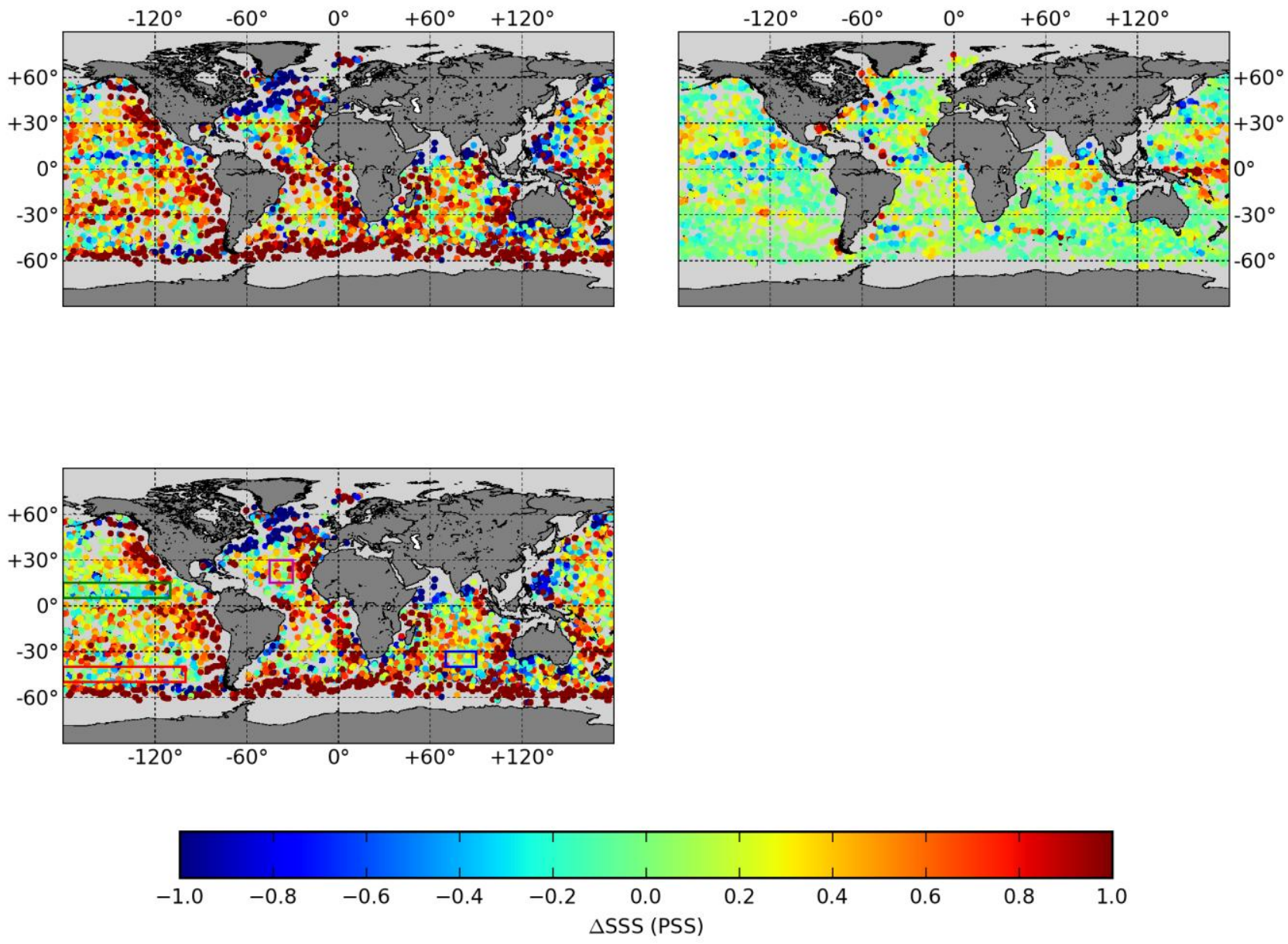

Fig. 2 : top left) Anomaly of SMOS SSS (colocated with ARGO floats) with respect to SSS climatology ; top, right) Anomaly of ARGO SSS with respect to SSS climatology; bottom) difference between SMOS SSS and ARGO SSS; color boxes indicate regions where we performed detailed comparisons. On these plots, all SMOS SSS colocated with one ARGO SSS have been averaged (equation 2); colorscale is saturated. 

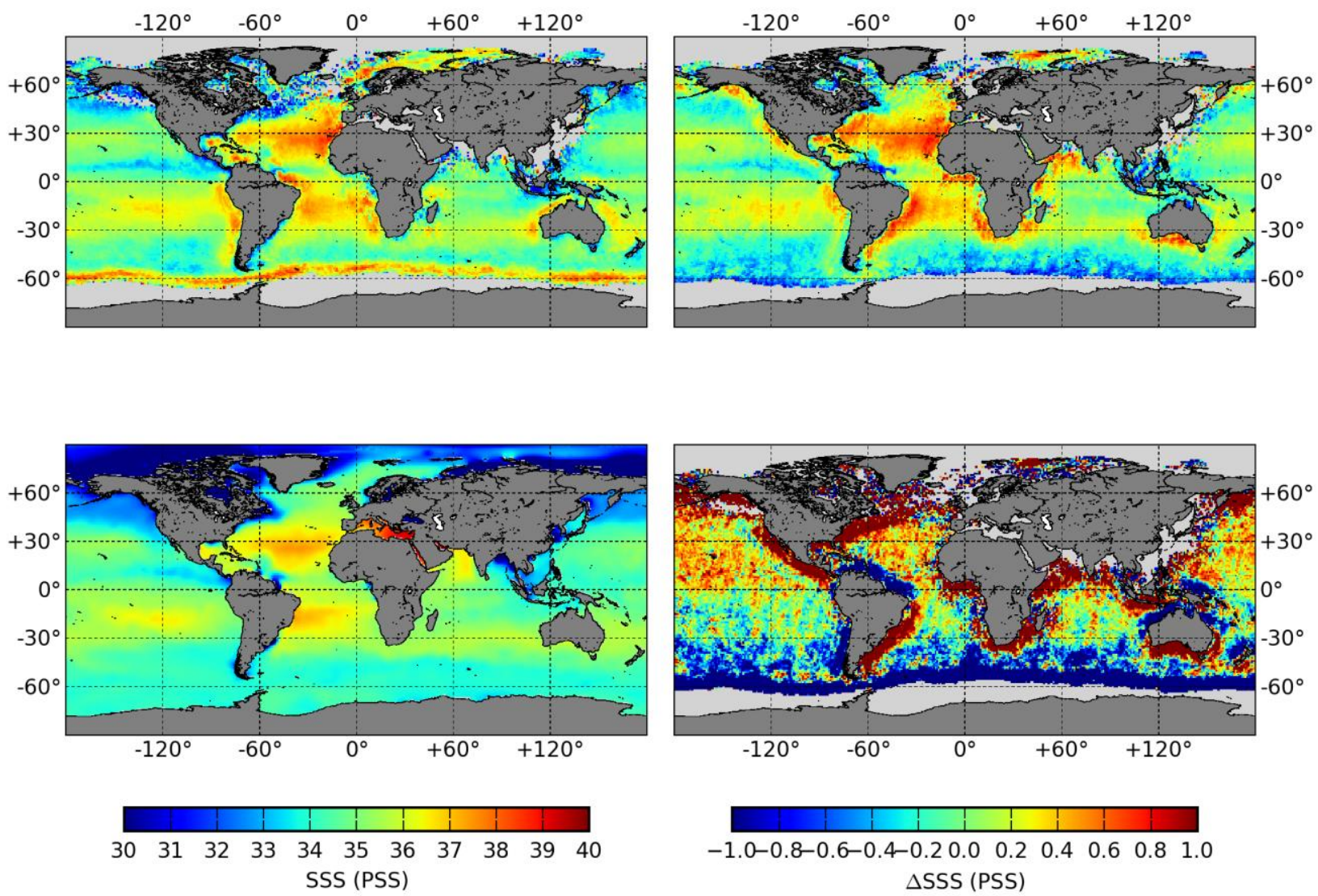

Fig. 3 : Top:Global maps of monthly SSS computed from SMOS measurements from 3 to 31 August 2010:top, left) using ascending orbits ; top, right) using descending orbits; bottom left) from WOA05 monthly climatology during August. Bottom right) Descending minus ascending SMOS retrieved SSS (colorscales are saturated). 

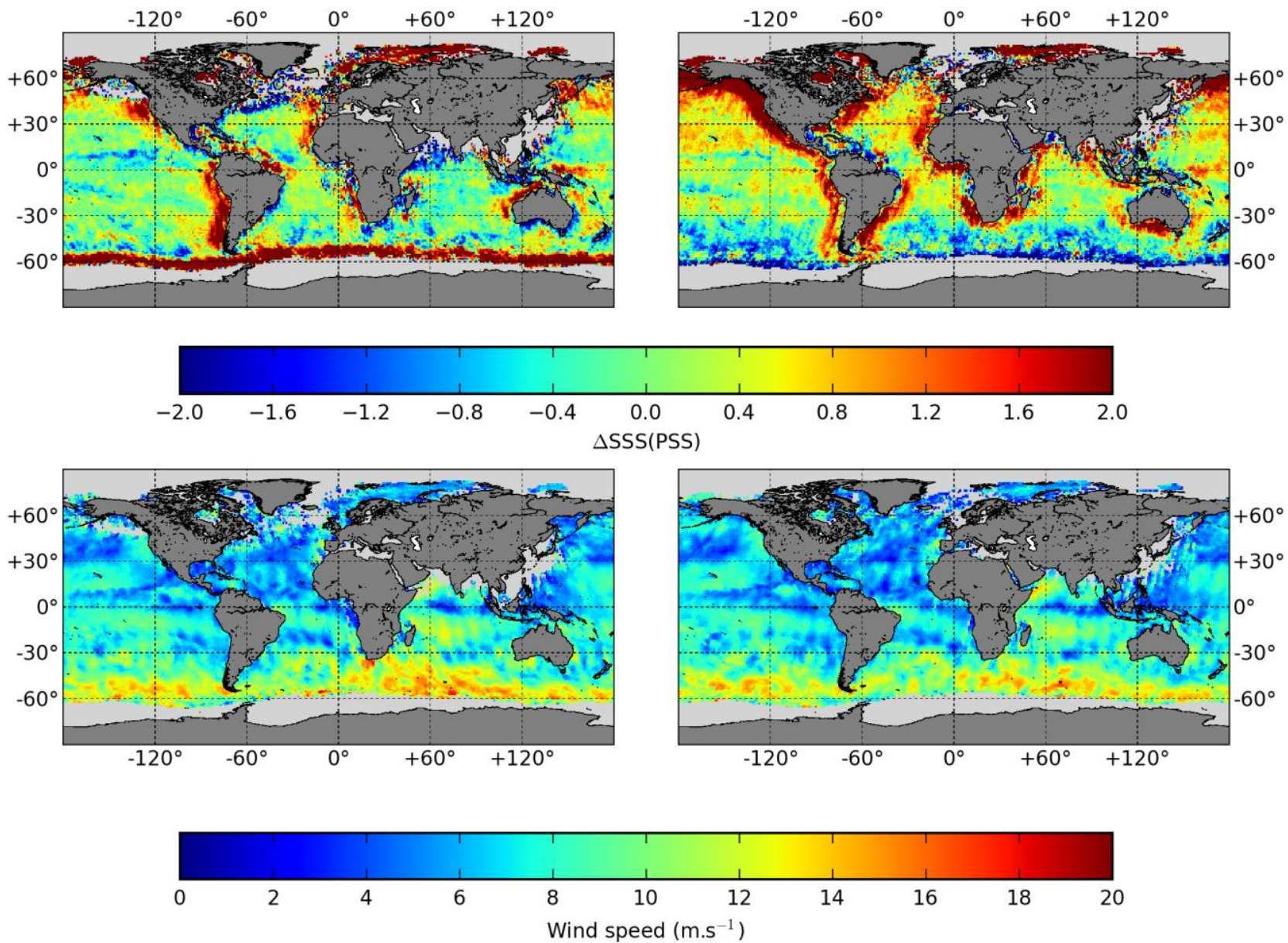

Fig. 4 : top) Maps of the differences between SMOS SSS from 4 to 13 August and the August climatology; bottom) ECMWF wind speeds associated with SMOS measurements. Left) ascending orbits; Right) descending orbits. (color scales are saturated)

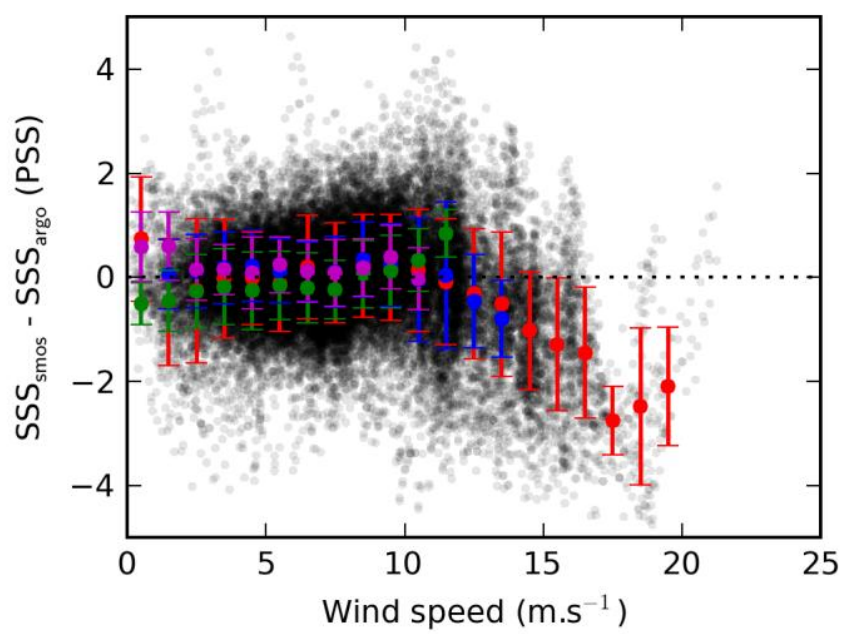

Fig. 5 : SMOS SSS (retrieved with model 1) - ARGO SSS as a function of wind speed. In order to reduce the scattering of the points, only SSS retrieved at $+/-300 \mathrm{~km}$ from the centre of the swath are used. The mean difference in classes of $1 \mathrm{~m} / \mathrm{s}$ wind speed plus and minus one standard deviation is plotted for classes containing more than 30 SMOS SSS in red for the South Pacific, in blue for the Southern Indian Ocean, in green for the tropical Pacific Ocean and in magenta for the subtropical Atlantic Ocean. 
Standard deviation of differences (SSSsmos-SSSargo) (3-12m/s)

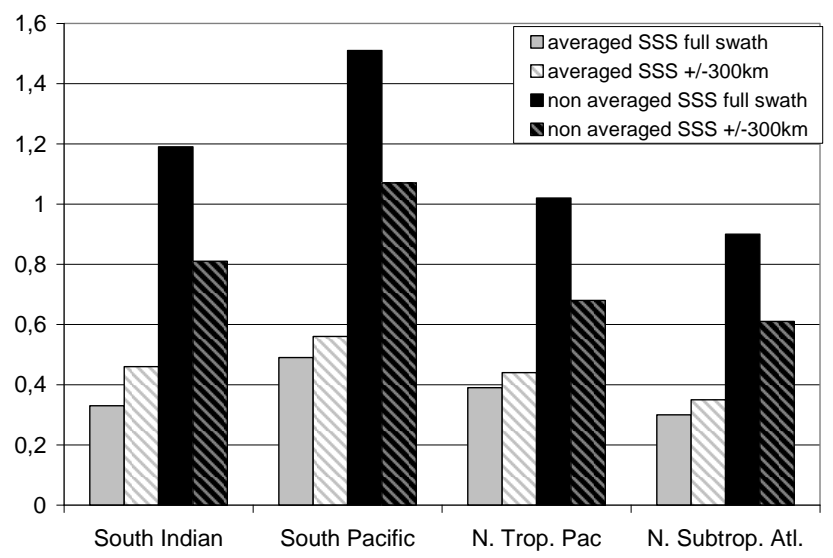

Fig. 6 : Errors (in pss) on SMOS retrieved SSS (non averaged) (dark) and on SMOS SSS averaged over 100kmx100km and 10days around ARGO SSS (grey). These statistics have been computed considering only the SSS retrieved at the center of the swath (diagonal lines) or over the whole $1200 \mathrm{~km}$ swath (plain); only SSS retrieved with wind speeds between 3 and $12 \mathrm{~m} . \mathrm{s}^{-1}$ have been considered.

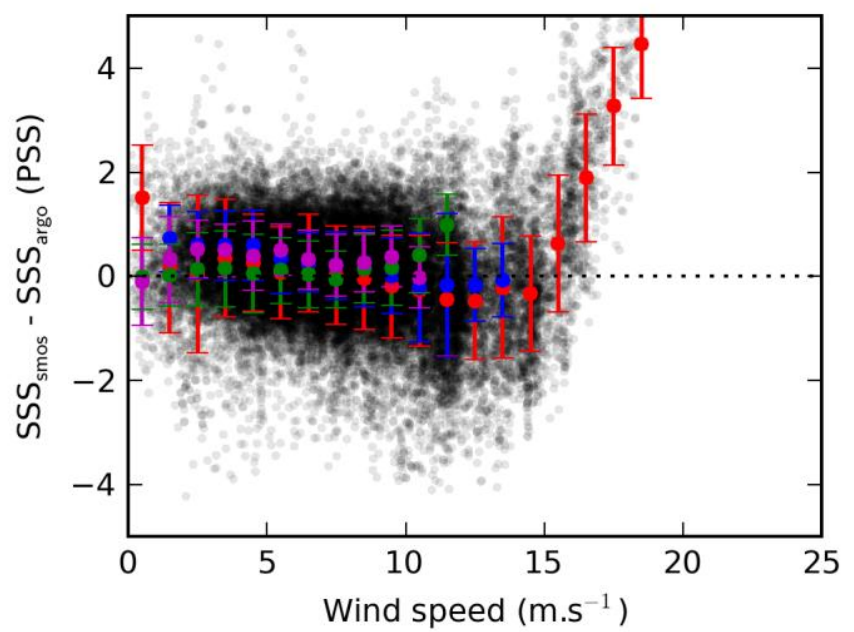

Fig. 7 : SMOS SSS retrieved with model 2 - ARGO SSS as a function of wind speed. In order to reduce the scattering of the points, only SSS retrieved at $+/-300 \mathrm{~km}$ from the centre of the swath are used. The mean difference in classes of $1 \mathrm{~m} / \mathrm{s}$ wind speed plus and minus one standard deviation is plotted for classes containing more than 30 SMOS SSS in red for the South Pacific, in blue for the Southern Indian Ocean, in green for the tropical Pacific Ocean and in magenta for the subtropical Atlantic Ocean. 


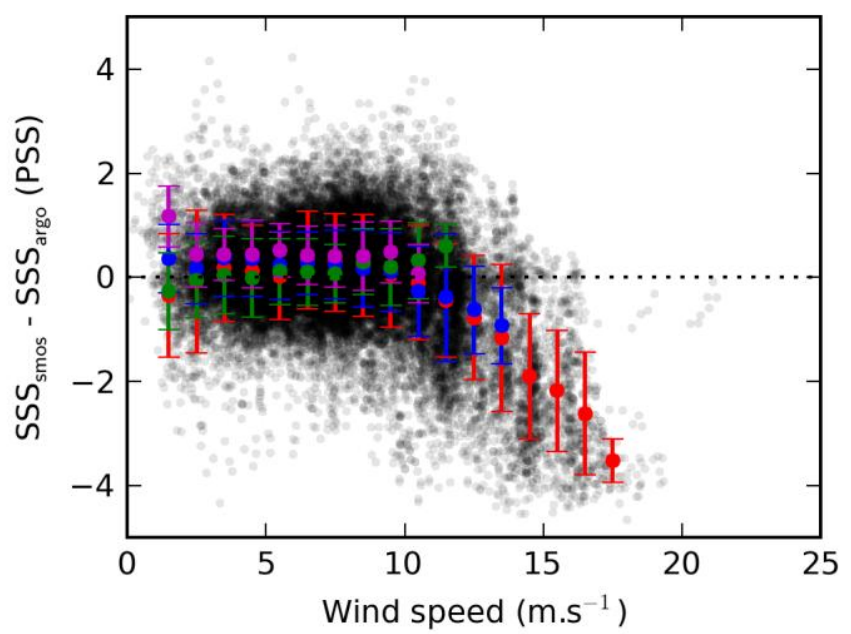

Fig. 8 : SMOS SSS retrieved with model 3 - ARGO SSS as a function of wind speed. In order to reduce the scattering of the points, only SSS retrieved at $+/-300 \mathrm{~km}$ from the centre of the swath are used. The mean difference in classes of $1 \mathrm{~m} / \mathrm{s}$ wind speed plus and minus one standard deviation is plotted for classes containing more than 30 SMOS SSS in red for the South Pacific, in blue for the Southern Indian Ocean, in green for the tropical Pacific Ocean and in magenta for the subtropical Atlantic Ocean.

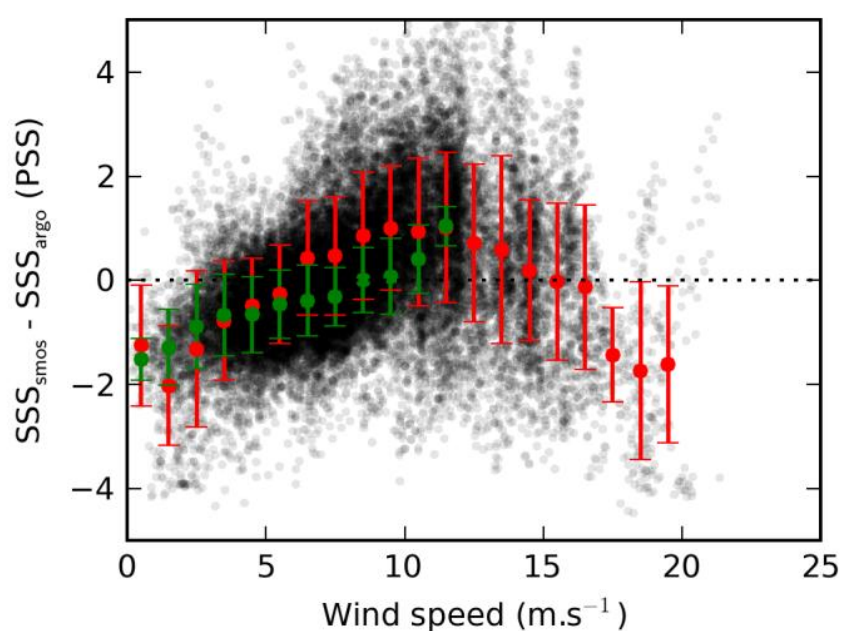

Fig. 9 : SMOS SSS retrieved with PALS model - ARGO SSS as a function of wind speed. The mean difference in classes of $1 \mathrm{~m} / \mathrm{s}$ wind speed $+/$ - one standard deviation is plotted for classes containing more than 30 SMOS SSS in red for the South Pacific and in green for the tropical Pacific Ocean. 

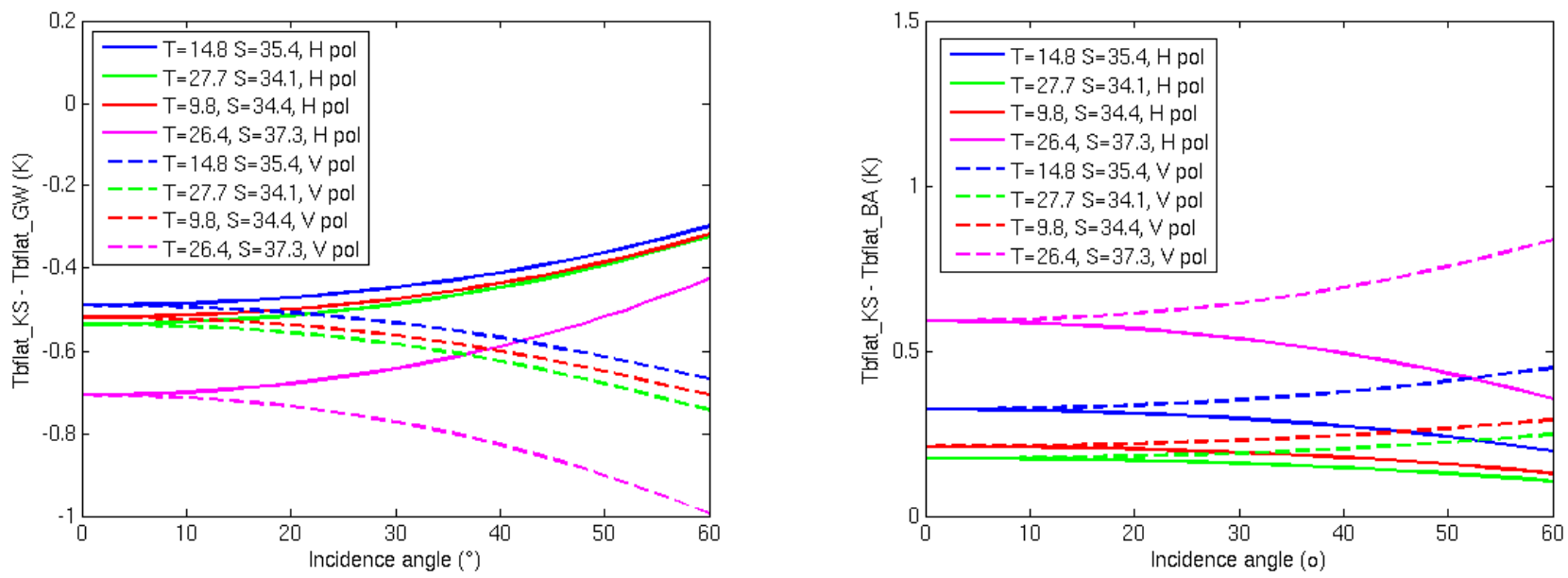

Fig. 10 : Difference between TB simulated with Klein and Swift model and (left) TB simulated with Lang et al. (2010) model, (right) TB simulated with Blanch and Aguasca (2004) model as a function of incidence angle for SSS and SST conditions in the South Pacific ocean (red), in the tropical Pacific Ocean (green), in the Southern Indian Ocean (blue) and in the subtropical Northern Atlantic (magenta) (note the different vertical scales on the two figures).

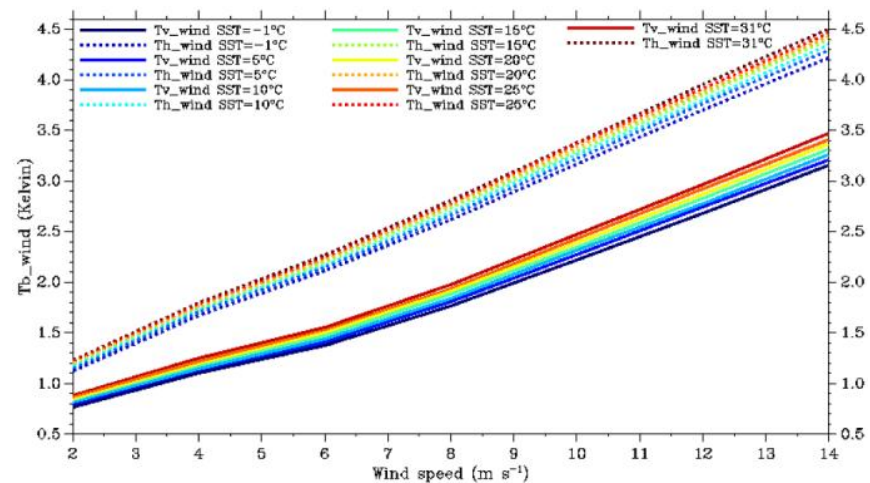

Fig. 11: Wind induced Tb simulated with model 1 (omnidirectional component) as a function of wind speed for SST between $-1{ }^{\circ} \mathrm{C}$ and $31^{\circ} \mathrm{C}$ (dashed line: horizontal polarisation; full line: vertical polarisation) at an incidence angle of $30^{\circ}$ and for SST varying between $-1^{\circ} \mathrm{C}$ (blue) and $31^{\circ} \mathrm{C}$ (red). 